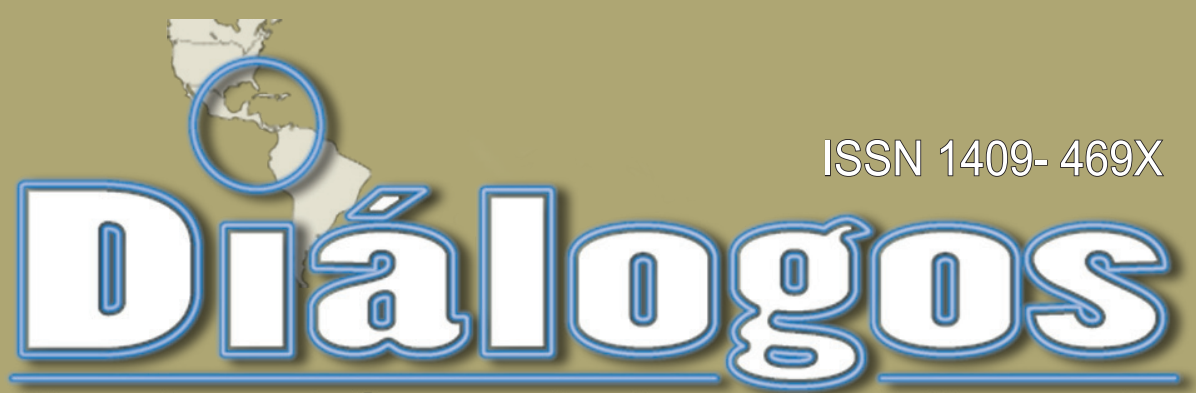

Revista Electrónica de Historia

Escuela de Historia. Universidad de Costa Rica Vol. 13 No. 2 Setjembre 2012 - Febrero 2013

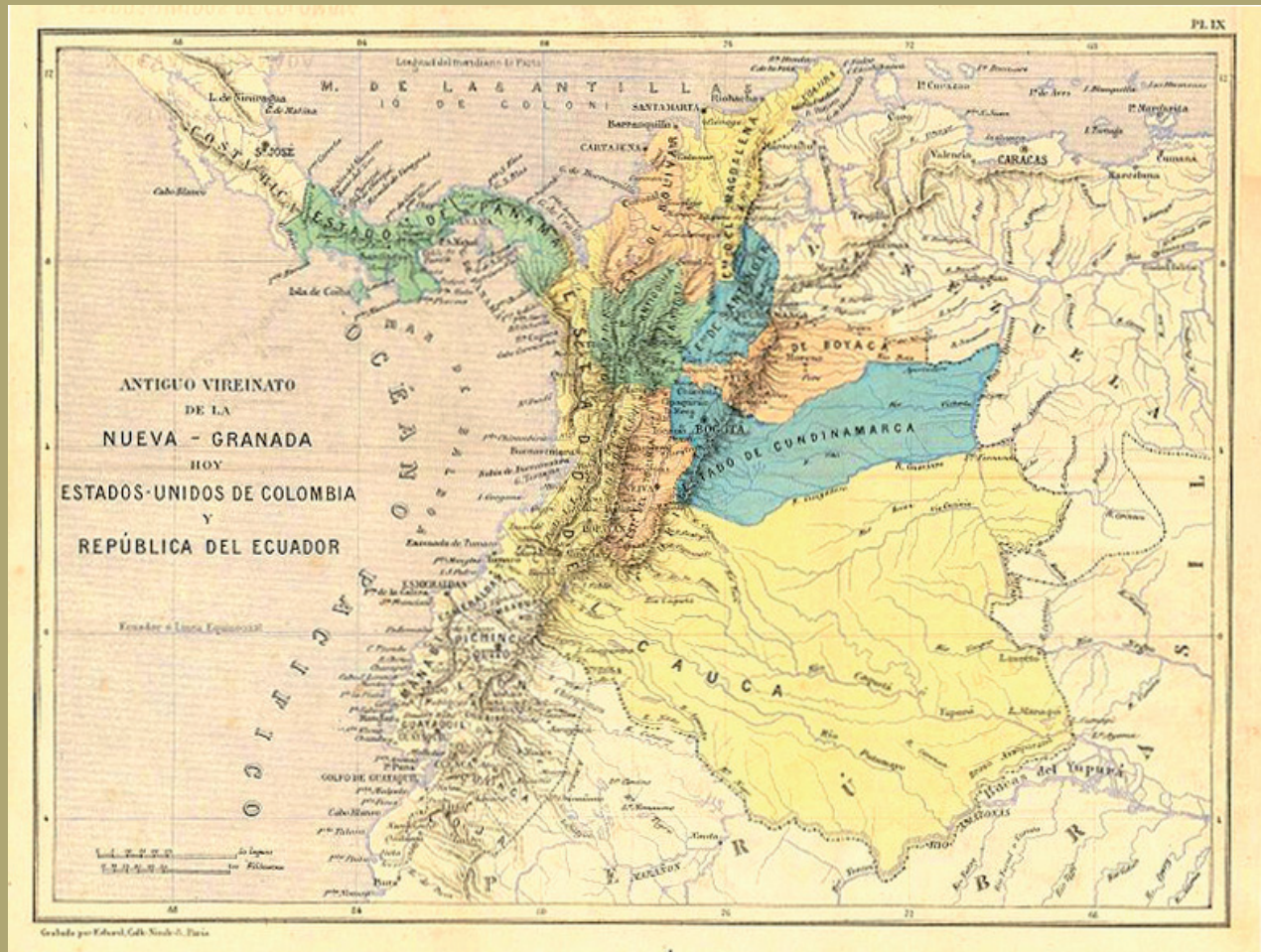

\title{
EL REFERÉNDUM DE LAS CALLES. LUCHA SOCIAL Y REFORMA DEL INSTITUTO COSTARRICENSE DE ELECTRICIDAD (COSTA RICA 2000)
}

Mauricio Menjívar Ochoa

Director de la Revista: Dr. Juan José Marín Hernández juan.marinhernandez@ucr.ac.cr

Editor académico: Dr. Ronny Viales Hurtado - ronny.viales@ucr.ac.cr Editor técnico: M.Sc. Marcela Quirós G. - marcela.quiros@ucr.ac.cr Asistente: Cindy Chaves U. http://historia.fcs.ucr.ac.cr/dialogos.htm 


\section{Miembros del Consejo Editorial:}

Dr. Juan José Marín Hernández, Catedrático. Director del Centro de Investigaciones Históricas de América Central. Universidad de Costa Rica.

Dr. Ronny Viales Hurtado. Catedrático. Historia Económica y Social. Universidad de Costa Rica. Director de la Escuela de Historia. ronny.viales@ucr.ac.cr

Dr. Guillermo Carvajal. Geografía Humana. Universidad de Costa Rica.

MSc. Francisco Enríquez. Historia Social. Universidad de Costa Rica.

MSc. Bernal Rivas Especialista en Archivística. Universidad de Costa Rica.

MSc. Ana María Botey. Historia de los movimientos sociales. Universidad de Costa Rica.abotey@gmail.com

\section{Miembros del Consejo Asesor Internacional:}

Dr. José Cal Montoya. Universidad de San Carlos de Guatemala.jecalm@correo.url.edu.gt

Dr. Juan Manuel Palacio. Universidad Nacional de San Martín.jpalacio@unsam.edu.ar

Dr. Eduardo Rey. Universidad de Santiago de Compostela.ereyt@usc.es

Dr. Heriberto Cairo Carou. Departamento de Ciencia

Política y de la Administración III - Universidad

Complutense de Madrid. hcairoca@cps.ucm.es

Dra. Rosa de la Fuente. Departamento de Ciencia Política y de la Administración III Universidad Complutense de Madrid rdelafuente@cps.ucm.es

Dr. Javier Franzé. Departamento de Ciencia Política y de la Administración III Universidad Complutense de Madrid. javier.franze@cps.ucm.es

Dr. Jaime Preciado Coronado Departamento de Estudios Ibéricos y Latinoamericanos. Universidad de Guadalajara japreco@hotmail.com

Dr. Gerónimo de Sierra. Vicerrector de la Universidade Federal da Integração Latino-Americana (UNILA) y Departamento de Sociología, Facultad de Ciencias Sociales de la Universidad de la República. geronimo@fcs.edu.uy

Dr. Antonio Palazuelos. Departamento de Ciencia Política y de la Administración III - Universidad Complutense de Madrid. palazuelosa@cps.ucm.es

Dr. Werner Mackenbach. Universidad Potsdam. werner.mackenbach@uni-potsdam.de
Dr. Guillermo Castro. Ciudad del Saber Panamá. gcastro@cdspanama.org

Dra. Natalia Milanesio. University of Houston.

nmilane2@Central.UH.EDU

Dr. Ricardo González Leandri. Consejo Superior de Investigaciones Científicas - España.

rgleandri@gmail.com

Dra. Mayra Espina. Centro de Estudios Psicológicos y Sociológicos, La Habana.mjdcips@ceniai.inf.cu

Dra. Montserrat Llonch. Departamento de Economía e Historia Económica Universidad Autónoma de Barcelona montserrat.llonch@uab.es

Dra. Estela Grassi. Universidad de Buenos Aires. estelagrassi@gmail.com

Portada:

Mapa de los Estados Unidos de Colombia y República del Ecuador: Volumen 13- No. 2, artículo "La libertad de elegir"... de Luis Alarcón M. y Jorge Conde C. Fuente: Les États-Unis de Colombie Ricardo Pereira, en http://www. banrepcultural.org/blaavirtual/cartografia

"Diálogos Revista Electrónica de Historia" se publica desde octubre de 1999.

\section{Diálogos está en los siguientes repositorios:}

Dialnet

http://dialnet.unirioja.es/servlet/revista?tipo_busqueda=CODIGO\&clave_revista=3325

Latindex

http://www.latindex.unam.mx/larga.php?opcion=1\&folio=12995;

REDALYC

http://redalyc.uaemex.mx/src/inicio/FrmBusRevs2.jsp?iEdoRev=2\&cvepai=11;

LANIC

http://lanic.utexas.edu/la/ca/cr/indexesp.html;

Repositorio de Revistas Universidad de Costa Rica http://www.latindex.ucr.ac.cr/

Directorio y recolector de recursos digitales del Ministerio de Cultura de España

http://roai.mcu.es/es/inicio/inicio.cmd

DOJAC Directory of open access \& Hybrid journals http://www.doaj.org/doaj?func=byTitle\&hybrid=1\&query=D

Biblioteca de Georgetown

http://library.georgetown.edu/newjour/d/msg02735.html

Asociación para el Fomento de los Estudios Históricos en Centroamérica

http://afehc.apinc.org/index.php?action=fi_aff\&id=1774 
Universidad de Saskatchewan, Canadá

https://library.usask.ca/ejournals/view/1000000000397982

\section{Monografias}

http://www.monografias.com/Links/Historia/more12.shtm

\section{Hispanianova}

http://hispanianova.rediris.es/general/enlaces/hn0708.htm

Universidad del Norte, Colombia

http://www.uninorte.edu.co/publicaciones/memorias/enlaces.html

Universidad Autónoma de Barcelona

http://seneca.uab.es/historia/hn0708.htm

Repositorio Invenia - Gestión del Conocimiento

http://www.invenia.es/oai:dialnet.unirioja.es:ART0000086144

Enlace Académico

http://www.enlaceacademico.org/biblioteca/revistas-en-formato-digital-centroamerica/

\section{Electronic Resources}

http://sunzi1.lib.hku.hk/ER/detail/hkul/3987318

Revistas académicas en texto completo

http://web.prw.net/ vtorres/

\section{Diálogos se anuncia en las siguientes}

instituciones y sitios académicos:

\section{Maestroteca}

http://www.maestroteca.com/detail/553/dialogos-revista-electronica-de-historia.html

\section{Biblioteca de Georgetown}

http://library.georgetown.edu/newjour/d/msg02735.htm
Asociación para el Fomento de los Estudios Históricos en Centroamérica

http://afehc.apinc.org/index.php?action=fi_aff\&id=1774

Universidad de Saskatchewan, Canadá

https:/library.usask.ca/ejournals/view/1000000000397982

\section{Monografias}

http://www.monografias.com/Links/Historia/more12.shtml

Hispanianova

http://hispanianova.rediris.es/general/enlaces/hn0708.htm

Universidad del Norte, Colombia

http://www.uninorte.edu.co/publicaciones/memorias/enlaces.html

Universidad Autónoma de Barcelona

http://seneca.uab.es/historia/hn0708.htm

Repositorio Invenia - Gestión del Conocimiento http://www.invenia.es/oai:dialnet.unirioja.es:ART0000086144

\section{Enlace Académico}

http://www.enlaceacademico.org/biblioteca/revistas-en-formato-digital-centroamerica/

\section{Electronic Resources}

http://sunzi1.lib.hku.hk/ER/detail/hkul/3987318

Revistas académicas en texto completo http://web.prw.net/ vtorres/

La revista electrónica Diálogos es financiada por la Vicerrectoría de Investigación de la Universidad de Costa Rica
Citado en Dialnet - Latindex-

Redilac- Directorio y recolector

de recursos digitales del

Ministerio de Cultura de España

cc) creative 



\title{
EL REFERÉNDUM DE LAS CALLES. LUCHA SOCIAL Y REFORMA DEL INSTITUTO COSTARRICENSE DE ELECTRICIDAD (COSTA RICA 2000).
}

\author{
Palabras claves \\ Movimientos sociales, “combo" del ICE, reforma del Estado, historia del siglo XX, Costa Rica
}

\section{Keywords}

Social movements, “combo” ICE, State reform, twentieth-century history, Costa Rica

Fecha de recepción: 22 de agosto, 2011 - Fecha de aceptación: 13 de abril, 2012

\begin{abstract}
Resumen
El artículo presenta un análisis de coyuntura sobre la lucha social desarrollada en el año 2000 debido a los intentos de reformar el Instituto Costarricense de Electricidad ("combo" del ICE). En la primera parte se procura comprender la dinámica de los actores sociales involucrados. Se analiza la manera en que se incorporaron a la lucha tanto los actores que rechazaban la reforma del ICE, como los que impulsaban su aprobación. También se abordan las negociaciones que dieron término al movimiento social de protesta en contra del "combo". En la segunda parte se presta atención a la llamada "Comisión Mixta", con asiento en la Asamblea Legislativa, creada para confeccionar un nuevo proyecto de ley sobre el ICE. También se analiza la forma en que la "representación social", incluida en la Comisión Mixta, buscó seguir articulada a los sectores sociales opuestos a la reforma.
\end{abstract}

\begin{abstract}
This article presents a situation analysis on the social struggle developed in 2000 because of the attempts to reform the Instituto Costarricense de Electricidad ("combo" ICE). The first part seeks to understand the dynamics of social actors. It is analyzed the way in which actors who rejected reform, as well as those that supported its approval, joined themselves into the struggle. It is also analyzed negotiations that finished social movement of protest against "combo". In second part attention is paid to the "Comisión Mixta", with seat in the Legislature, created to prepare a new draft law on the ICE. It also discusses how "social representation", included in the "Comisión Mixta", sought to remain connected to social sectors opposed to reform.
\end{abstract}




\section{EL REFERÉNDUM DE LAS CALLES. LUCHA SOCIAL Y REFORMA DEL INSTITUTO COSTARRICENSE DE ELECTRICIDAD (COSTA RICA 2000)*}

Mauricio Menjívar Ochoa

\section{INTRODUCCIÓN}

El 16 de marzo del año 2000 quizá sea una fecha insuficientemente posicionada en la memoria de las luchas sociales recientes. ${ }^{1}$ En la madrugada de ese día, grupos de agricultores realizaron bloqueos de vías en diferentes lugares del país. De ellos, el más emblemático fue el de la carretera a Cartago a la altura del Alto de Ochomogo. Sin duda se trataba de un punto estratégico por sus repercusiones sobre la economía: impedía el acceso a la estación de la Refinería Costarricense de Petróleo, ahí ubicada, así como el desplazamiento del transporte privado y público entre San José y Cartago y otros puntos al sur del país. Pero, sobre todo, dicho bloqueo tuvo una trascendental implicación política: por su visibilidad y cercanía con los principales centros de población, desencadenó la solidaridad de amplios sectores sociales con la causa campesina. Al mismo tiempo, confluyó con una de las mayores protestas sociales en la historia reciente del país: la defensa del Instituto Costarricense de Electricidad (ICE) bajo el espíritu de un desarrollo social con bases redistributivas y de inclusión.

En efecto, hasta este momento, y desde que se iniciaron los procesos de redefinición estructural de la sociedad costarricense en la década de 1980, nunca en el país se había presenciado una escena de deliberación democrática y de participación ciudadana como durante los meses de marzo y abril del año 2000. Habría que remontarse a las luchas comunales de 1983, desarrolladas en oposición a las alzas en las tarifas de la electricidad, para encontrar un movimiento unitario de grandes dimensiones; o a las luchas bananeras de inicios de esa misma década y a la lucha magisterial y sindical de 1995, para hallar niveles similares de combatividad y presencia política de los sectores populares y medios. ${ }^{2}$ Pero, posiblemente, ninguna otra coyuntura del último tercio del siglo XX pueda ser comparable con la irrupción de los habitantes del país al escenario político nacional, ${ }^{3}$ constituidos en ciudadanos por derecho propio. ${ }^{4}$ Aglutinados alrededor del simple lema "ICE sí, Combo no", la ciudadanía tomó las calles y concretó el referendo popular que nunca fue.

La relevancia que tiene la coyuntura de lucha social en contra de la Ley para el Mejoramiento de los Servicios Públicos de Electricidad y Telecomunicaciones $y$ de la Participación del Estado, mejor conocido como "combo del ICE", 5 puede 
medirse no sólo en términos del interés ciudadano en la conducción del gobierno del país, del cual es difícil encontrar parangón; sino también a partir de los logros que tiene el ejercicio de esta participación: un importante grado de apertura del sistema político a las demandas de la ciudadanía. De esto da cuenta la creación de la Comisión Especial Mixta en la Asamblea Legislativa que acogió en su seno a una Representación Social de una parte de los sectores movilizados. Este mecanismo brindó una salida al conflicto que contrapuso a buena parte de los y las habitantes con los poderes ejecutivo y legislativo y, a su vez, pretendió conformarse en el ente encargado de canalizar, con una mayor participación de la ciudadanía, las propuestas en torno al futuro de ICE.

Para contribuir a la comprensión de este importante proceso de lucha social y algunas de sus repercusiones sobre la vida política posterior inmediata, el presente análisis de coyuntura se divide en dos partes. ${ }^{6}$ La primera parte se centra en el estudio de la lucha social, una vez aprobado el "combo" en primer debate, que es la parte principal de esta investigación. Se procura comprender la dinámica de los distintos actores sociales en relación al mismo, teniendo en cuenta que el país asistió a una verdadera confrontación entre grandes conglomerados sociales, y no sólo entre grupos de interés específicos. En este sentido, se busca explicar porqué y de qué manera se incorporaron tanto los actores que rechazaban la reforma del ICE, como los que impulsaban su aprobación. Especial interés se tiene en explicar los factores que propiciaron la confluencia de sectores tan heterogéneos alrededor del rechazo del "combo". Esto cobra relevancia en un momento en que la desarticulación social de los sectores comunales, sindicales, estudiantiles, ecologistas y demás, constituía la tónica. La masiva incorporación social de la diversidad y las estrategias de lucha, contribuyen a explicar, igualmente, el éxito de la protesta. Esta parte cierra con una reflexión sobre la inédita negociación que tuvo lugar en el Tribunal Supremo de Elecciones (TSE).

La segunda parte busca analizar algunos elementos de la dinámica posterior a la negociación entre los sectores sociales opositores y las elites económicas y políticas. Quizá uno de los elementos más relevantes sea que el "combo" terminó de ser derrotado en la Sala IV, en tanto fue declarado inconstitucional. No obstante, en esta última parte también resulta de gran interés analizar un elemento central de los acuerdos tomados en el TSE por las partes en conflicto. Se trata de la llamada "Comisión Mixta" (CM), con asiento en la Asamblea Legislativa, y que fue creada con el mandato de confeccionar nuevo proyecto de ley sobre el ICE. La gran relevancia de esta CM es que incorporó a una "representación social" de los sectores antireforma. Entender las dificultades enfrentadas por la CM, es otro de los objetivos de esta parte final. Igualmente relevante es analizar la forma en que la "representación social", incluida en la CM, buscó seguir articulada a los sectores sociales a los que, precisamente, debía representar en la Asamblea Legislativa. Tales sectores, valga 
adelantar, muy rápidamente se desarticularon. Finalmente, este trabajo realiza una reflexión sobre las repercusiones políticas de la lucha. Quizá el principal resultado fue la convicción social respecto del imperativo de avanzar hacia formas participativas de democracia. Este era uno de los mandatos del referéndum de las calles.

\section{LA LUCHA SOCIAL EN CONTRA DEL “COMBO”}

\section{El inicio de la movilización social y la gestación de liderazgos de nuevo tipo}

A finales de 1999, el dictamen afirmativo del "combo" en una Comisión Especial de la Asamblea Legislativa, hacía prever la inminente aprobación del proyecto en primer debate. A partir de aquí, comenzó a perfilarse una articulación más clara de algunos líderes de los sectores que, posteriormente, tendrían protagonismo en el movimiento social en contra del "combo". Entre ellos: el sector estudiantil universitario, los sindicatos del ICE, ANEP, miembros de la Pastoral Social de la Iglesia y representantes comunales de Pérez Zeledón, ecologistas, diputados de la Fracción de Fuerza Democrática, y otra serie de sindicatos.

La articulación de los sectores sociales arrastraba, sin embargo, la disputa por el liderazgo del movimiento en gestación, elemento característico en algunos movimientos sociales precedentes. Esta situación condujo a que en los primeros dos meses del año 2000 existieran dos frentes. Por una parte, se gestó el "Frente Cívico" integrado por dos sectores: en primer lugar, miembros del llamado Comité Sociolaboral (en su mayoría sindicatos que participaron en la Concertación, convocada por el Gobierno en el año 1998) y, en segundo lugar, el Foro Social y Nacional de Lucha (sindicatos no participantes en el proceso de Concertación). Tanto en el Comité Sociolaboral como en el Foro Social y Nacional de Lucha confluyeron sindicatos del sector público como los del magisterio, los del sector salud, de las universidades, del ICE, entre otros.

Por otra parte, se conformó la "Liga Cívica", espacio de confluencia para algunos sindicatos del ICE, grupos ecologistas, representantes de la comunidad de Pérez Zeledón y Rivas, el Comité de Defensa de la Institucionalidad, el Grupo Soberanía y otros sectores organizados. ${ }^{7}$ La existencia paralela de ambas instancias mostró una diferencia de estilo organizativo, de afinidades en la dinámica de trabajo, de procedimientos de toma de decisiones y, en gran parte, de los sectores representados.

No obstante estas diferencias, el movimiento social mostró a la larga una serie de fortalezas que, conjugadas, permitirían explicar la gran envergadura del movimiento social y el fuerte apoyo que le brindó a éste la opinión pública. La primera y quizá la más relevante de las fortalezas, residió en el motivo de la convocatoria 
lanzada por los autodenominados "sectores sociales": el Instituto Costarricense de Electricidad. El eslogan que contrapone al ICE con el plan gubernamental que buscaba su reforma y la inclusión de la participación privada mostró, con gran claridad, la gran capacidad de convocatoria que esta institución tenía entre la ciudadanía. De esta suerte, el ICE pareció prestar su legitimidad social al movimiento de lucha, en la medida que ha sido una institución clave dentro del desarrollo del Estado de bienestar de segunda posguerra. En el plano simbólico, esto pareciera hacerla parte constitutiva de la democracia costarricense y en un asunto de identidad nacional.

El uso de la denominación "cívica", por parte de los dos frentes conformados, denota el intento de hacer propio estos elementos asociados a la democracia y a la identidad costarricense. A diferencia de luchas más sectoriales como la del magisterio y de otros sindicatos, este recurso a "lo cívico" mostró tener mayor sustento debido al mayor rechazo de la reforma. Una encuesta telefónica realizada durante la lucha social mostró que más de la mitad de las personas entrevistadas $(53,3 \%)$ estaba en contra del "combo" y que un 10,4\% estaba en desacuerdo con algunos aspectos de la ley y de acuerdo con otros. ${ }^{8}$ También mostró que el desacuerdo con el "combo" estaba más difundido en el resto del país $(59,7 \%)$ si se le comparaba con el Área Metropolitana $(51,3 \%)$, lo cual podría explicarse por el hecho de que "en el caso de los pobladores rurales, el mayor significado otorgado a los servicios básicos y el carácter más reciente de la electrificación y la telefonía podría combinarse con temores de exclusión ante la eventual privatización de los servicios". ${ }^{9}$ Resulta no poco significativo que, una vez terminada la lucha social, creció el desacuerdo con el Combo, como lo comprobó una segunda encuesta. Ahora el 62,9\% estaba en desacuerdo con el combo -frente al 53\% durante el proceso de lucha. En aquel momento, el 78,5\% de las personas entrevistadas consideró que el ICE debía seguir perteneciendo al Estado. ${ }^{10}$

Junto con la legitimidad que transfirió el ICE al movimiento, contribuyó la voluntad política expresa por parte de las organizaciones sociales de no anteponer luchas de carácter reivindicativo y sectorial a la consigna de "ICE si, Combo no", buscando darle al movimiento un carácter cívico. A propósito de esto cabe como excepción la lucha que paralelamente emprendieron campesinos de la Corporación Hortícola Nacional, ${ }^{11}$ quienes el 16 de marzo del 2000 -cuatro días antes de la aprobación del "combo" en primer debate legislativo- bloquearon la carretera San José-Cartago a la altura del Alto de Ochomogo. Estos sectores pedían al Gobierno establecer medidas para proteger el sector agrícola, tales como la elevación de los impuestos a la importación de papa y cebolla, así como declarar emergencia nacional a los créditos agrícolas morosos. Esta excepción debe ser vista en una clave similar a la del ICE, pues la lectura social existente en el momento destacó a los campesinos como otra parte fundante de la democracia costarricense. Por 
esta razón, el llamado posterior que hizo la Corporación Hortícola en defensa del ICE, lejos de ser un punto en contra del movimiento, se constituyó en un detonante adicional de la protesta y en un factor de convocatoria y de aglutinación social.

La gran diversidad de actores, lejos de ser obstáculo, se convirtió en factor de decisiva importancia para el avance del movimiento, pues llevó a la necesidad de establecer una coordinación horizontal no jerárquica de las acciones, en la que cada una de las organizaciones y sectores sociales involucrados debió tener gran flexibilidad hacia las iniciativas del resto. Si bien esto no significó la eliminación de las discrepancias ni de las rivalidades entre algunos de los sectores, esta forma de acción conjunta tuvo implicaciones en la creación de nuevas formas de liderazgo no basadas en la decisión de una cúpula, sino en la existencia de múltiples centros de toma de decisión-acción. Es decir, la diversidad de sectores y la amplitud geográfica del movimiento obligó a actuar de manera flexible y no excluyente, donde cada sector aportó a partir de sus propias posibilidades organizativas.

Otra condición que confluyó con el movimiento fue el descontento acumulado de la ciudadanía con el gobierno y con los partidos políticos. Así, un $93.7 \%$ de la población consideró que las protestas eran formas de decir al Partido Unidad Social Cristiana y al Partido Liberación Nacional que las y los costarricenses estaban cansados de lo que habían hecho con el país. En este sentido, el movimiento social en contra del "combo" podría haber funcionado como catalizador del descontento de la ciudadanía y no sólo del sector social que participó directamente en las protestas, pues un $84 \%$ consideraba que las manifestaciones eran una muestra de disconformidad general contra el Gobierno y otras autoridades del país. ${ }^{12}$

También fueron catalizadores del descontento la desconfianza de las medidas gubernamentales y la percepción de que mediante éstas no se gobernaba a favor del pueblo, sino de los intereses de los políticos y de ciertos sectores. Una gran parte de la población (60\%) tomaba con desconfianza las medidas gubernamentales relativas al "combo" pues eran percibidas como un intento de "engañar al pueblo". Adicionalmente, la mayoría $(93,4 \%)$ consideraba que las protestas se producían porque los Gobiernos y los políticos se habían olvidado de las necesidades de la población ${ }^{13}$ y una gran parte $(73,9 \%)$ pensaba que los que promovían la privatización del ICE querían hacer su propio negocio. ${ }^{14}$ Ciertamente, la privatización y venta del ICE era percibida como una de las principales causas de la protesta (53\%). ${ }^{15}$

Para otros sectores, el estilo de gobierno y la forma de tomar decisiones, más que la reforma, era lo que estaba en tela de juicio. Éste se caracterizaba por ser un proceso sin claridad, manejado sin información ni comunicación con el pueblo (era así para un $7.9 \%$ y $3.3 \%$ respectivamente), y sin escuchar su voz (5.7\%). También se objetaba la forma en que había sido aprobado el "combo" (10.6\%).

Otros factores más puntuales, pero no menos significativos, jugaban a favor de la protesta y en contra de las medidas del gobierno: el cansancio del pueblo 
$(3,7 \%)$, el alto costo de la vida $(2,7 \%)$, la disconformidad ciudadana $(2,7 \%)$ y el miedo al aumento en servicios públicos un $(2,6 \%) .{ }^{16}$ En suma, la protesta en contra del "combo" sirvió como catalizador de un amplio descontento social. Las condiciones para una amplia alianza estaban dadas.

\section{La confluencia de la diversidad}

La amplitud de tal alianza y su carácter no siempre orgánico, hace difícil hacer un recuento de todos los actores que, de una u otra manera, se involucraron en el movimiento social. Tampoco es posible saber con exactitud el momento en que se integraron ni el aporte preciso que realizaron. En todo caso, es posible hacer un recuento de ciertos actores y reseñar algunas de sus contribuciones.

No cabe duda que la fracción del partido Fuerza Democrática mantuvo su oposición al proyecto durante toda su tramitación, y se articuló a los sectores populares durante el movimiento social. Fue uno de los sectores políticos formales de mayor visibilidad, junto con los sindicatos del sector público. Entre estos últimos jugaron un papel decisivo en el seguimiento legislativo del Combo los sindicatos del ICE, aglutinados en el Frente Interno de Trabajadores (FIT). El FIT también desarrolló un rol relevante en la organización del movimiento y en los actos de protesta en el ámbito nacional. Sin poder enumerar a todos los sindicatos presentes en el movimiento, cumplieron un papel relevante el Sindicato de Empleados Universitarios (SINDEU), la Unión Nacional de Empleados de la Caja y de la Seguridad Social (UNDECA) -que en varios momentos paralizó total o parcialmente diferentes centros del sistema de salud-, la Asociación Nacional de Empleados Públicos y Privados (ANEP), el Sindicato de Educadores Costarricense (SEC) y el Sindicato Patriótico de la Educación (SINPAE). Estos dos últimos sindicatos fomentaron la movilización en los centros educativos. El SINPAE, en particular, jugó un papel facilitador en la movilización de estudiantes de secundaria aglutinados en el Frente de Estudiantes de Secundaria (FES). También confluyeron trabajadores y trabajadoras del Instituto Nacional de Seguros (INS), Acueductos y Alcantarillados (AyA), El Sindicato de Trabajadores del Instituto Nacional de Aprendizaje (SITRAINA), entre otros.

Mención especial dentro del movimiento sindical merece la Federación de Trabajadores Limonenses (FETRAL), por su rol de gran importancia en la incorporación de los gremios y otros sectores de esa provincia. Esta organización, cabe recordar, no brindó su apoyo a la lucha que el magisterio y otros sindicatos del sector público emprendieron en el año 1995. En aquella ocasión, estos sectores se oponían al "pacto Figures-Calderón", que buscaba reformar la ley de pensiones del magisterio y privatizar o cerrar varias instituciones del Estado. Entonces, la FETRAL negoció una agenda propia con el gobierno en el contexto de una gran efervescencia social. ${ }^{17}$ 
En el 2000, en cambio, la FETRAL convocó una huelga general en Limón que comenzó el lunes 3 de abril. Inmersa en circunstancias de búsqueda de espacios de diálogo, esta medida se constituyó en una fuerte presión para el Gobierno, debido al apoyo y a la tradición de lucha que esta organización tiene en el Cantón Central del Limón. Este frente aglutinaba, entre otros, a trabajadores y trabajadoras de la Junta de Administración Portuaria y Desarrollo de la Vertiente Atlántica (JAPDEVA), de los muelles y de la Refinadora Costarricense de Petróleo. Sin duda, se trataba de sectores claves por su incidencia en la economía nacional.

Las Pastorales Sociales de diversas zonas del país se incorporaron en favor del movimiento, jugando un papel de gran relevancia en la legitimidad del movimiento en las comunidades y entre los padres y madres de familia, lo cual abonó la participación de las y los jóvenes. ${ }^{18}$ Es de destacar la participación de la Diócesis de San Isidro del General, ${ }^{19}$ cuyos presbíteros exteriorizaron ante la opinión pública su oposición al plan del ICE señalando que la propuesta de apertura del ICE significaba traspasar al ámbito privado las telecomunicaciones. Ello pareció tener incidencia en la incorporación posterior de otras pastorales. La emisora de la Pastoral de San Isidro del General, Radio Sinaí realizó en la coyuntura una labor de información y discusión de las implicaciones del proyecto, así como de divulgación general del movimiento.

Los grupos ecologistas, aglutinados en La Federación Costarricense por la Conservación de la Ecología (FECON) y el Frente Nacional por los Bosques ${ }^{20}$ se incorporaron a partir de su oposición a la depredación del ambiente y las repercusiones sociales y ambientales del "combo". Estas organizaciones se opusieron a la autorización para que empresas públicas y privadas desarrollaran proyectos energéticos en áreas protegidas y que pudieran expropiar propiedades para hacerlo, entre otros asuntos. ${ }^{21}$

También se unieron a las acciones de protesta, múltiples grupos organizados de la sociedad civil tales como el movimiento de mujeres -uno de los cuales conformó una instancia denominada "Mujeres Contra el Combo"-; otros colectivos más pequeños -algunos más duraderos que otros-, como "Las y los nadies", Soberanía, Grupo Germinal, entre otros.

Si bien no se debe sobredimensionar el papel de los estudiantes universitarios y de las mismas universidades públicas en esta lucha, pues sólo representan dos sectores dentro de una movilización mucho mayor, interesa aquí entrar en un detalle particular al respecto. En primer lugar podría decirse que, en este período, se produjo un resurgimiento del movimiento estudiantil universitario en la escena política nacional. Las y los estudiantes de la Universidad de Costa Rica (UCR), Universidad Nacional (UNA), del Instituto Tecnológico de Costa Rica (ITCR), y de la Universidad Estatal a Distancia (UNED) -en menor medida- mostraron un gran protagonismo en las diversas acciones de protesta registradas en el combo: bloqueos, 
manifestaciones, huelga de hambre, etc. ${ }^{22}$ La labor del movimiento estudiantil de la Universidad de Costa Rica, posiblemente el de mayor presencia entre los movimientos, se desarrolló en articulación con los frentes sociales. Contribuyó con la proyección de las Universidades Públicas hacia la comunidad nacional, por medio de foros de discusión y divulgación sobre el Combo y en el trabajo de información en comunidades y colegios. Estos últimos, asumieron una participación activa en bloqueos y manifestaciones en diferentes puntos del país, lo cual representó el punto máximo que en el período viviera la Federación de Estudiantes de Secundaria, organización que aglutinaba estudiantes de múltiples colegios.

Debe señalarse que existieron sectores estudiantiles con posiciones heterogéneas al respecto del movimiento y de la participación universitaria en el movimiento social. Los presidentes de los Consejos de Estudiantes de Agronomía, Economía e Ingeniería de la Universidad de Costa Rica, enviaron una carta pública al entonces rector, Gabriel Macaya, a raíz de su participación en el movimiento. Este sector sostenía que la imagen de la comunidad universitaria caía en descrédito "al actuar de una manera no estructurada, quizá prematura, al aliarse con grupos que representan los más variados intereses y que no necesariamente responden a los de la Institución". ${ }^{23}$ Por otra parte, un sector estudiantil dentro de la Universidad de Costa Rica (UCR) difirió respecto de la forma de trabajo de la Federación de Estudiantes, lo cual generó "división en el movimiento estudiantil, pues el grupo que por lo general no estaba de acuerdo con las decisiones tomadas se separó y conformó la 'Coordinadora Estudiantil Alternativa' ". ${ }^{24}$

Dentro de marco institucional universitario, el Consejo Universitario de la UCR y el Consejo Institucional del ITCR, acordaron manifestar su posición en contra del Combo, ${ }^{25}$ e hicieron un "vehemente llamado al pueblo costarricense y a los grupos organizados de la sociedad civil, a las comunidades universitarias y a todos los integrantes del Sistema Educativo Nacional, a ejercer todas las presiones legítimas a su alcance para lograr el retiro de este proyecto de la corriente legislativa". El pronunciamiento hecho por estos Consejos proveyó un marco institucional óptimo para la incorporación de ambas instituciones al movimiento en contra del "combo", pues acordaron que la administración Superior de la UCR y del ITCR proporcionaría las facilidades necesarias a la comunidad institucional para que se sumaran a la lucha. Sin embargo, el ITCR paralizó sus actividades, lo que significó una participación no orgánica de los diferentes sectores que lo conformaban, mientras que la UCR implementó la figura de "paro activo", en alusión al permiso institucional para participar en las actividades organizadas en el marco del movimiento, que implicaba la presencia de estudiantes, funcionarias y funcionarios en el campus. Ello potenció las actividades del sector universitario en el marco del movimiento, ${ }^{26}$ como también se pudo comprobar -en el caso de la UCR- en la lucha social de las universidades del año 1991 a favor de su presupuesto. ${ }^{27}$ 
La Universidad de Costa Rica impulsó la discusión sobre el proyecto del Combo, realizando desde el 23 de marzo, una gran cantidad de foros de análisis con especialistas y actores involucrados, contribuyendo de esta manera al debate nacional sobre el tema. ${ }^{28}$ Esta estrategia de difusión fue desarrollada a partir de la afirmación gubernamental acerca de la desinformación generalizada que existía entre las personas manifestantes.

Existen elementos para pensar que la posición asumida por la Universidad de Costa Rica brindó otro punto a favor de la legitimidad del movimiento, al brindarle a la opinión pública un sustento académico a la oposición al Combo. Un indicador a propósito de esto fue la percepción favorable que la opinión ciudadana tuvo sobre las Universidades Estatales, opinión que, sin embargo, podría responder también al papel que estos centros de educación superior jugaron en la salida negociada al conflicto, como se verá más adelante.

Pero, sin duda, el mayor testimonio de la lucha social, debe medirse en las calles, sitio donde confluyeron ciudadanos "a pié", muchos de ellos posiblemente sin filiación organizativa en las instancias señaladas o sin pertenencia a organización alguna.

\section{Las acciones de protesta del movimiento social opositor al "combo"}

La presencia de gran cantidad de actores sociales, la articulación y confluencia en torno a un solo objetivo común, la coordinación no jerárquica y la diversidad de centros de toma de decisión-acción, podrían considerarse como ingredientes que fortalecieron la participación de la ciudadanía en el período. Podría decirse, además, que estos fueron mecanismos que contribuyeron a sortear el problema de falta de representatividad existente en el país, pues no hubo una sola organización que pudiera reclamarse como la cabeza del movimiento.

Y ciertamente los sindicatos -uno los sectores más “orgánicos” de la sociedad civil, posiblemente después de las cámaras empresariales- estaban muy lejos de poder constituirse en el principal aglutinador inicial de la protesta. Podría pensarse que su poca legitimidad social en este momento, se expresó en que la tasa de sindicalización se encontraba en su punto más bajo en los últimos dieciséis años. En 1984 sólo el $15,7 \%$ de la población ocupada se encontraba afiliada a algún sindicato, proporción que a juicio de Ana María Botey era baja. ${ }^{29}$ En 1996, año siguiente del movimiento de maestras/os y de los sindicatos del sector público, la proporción era de $14,4 \%$. Para el año 2000 apenas un 10,1\% de la población ocupada pertenecía a algún sindicato. ${ }^{30}$

De modo que, para los sectores opositores a la reforma fue fundamental que en gran cantidad de comunidades se generara una articulación de sectores comunales con organizaciones sindicales, estudiantiles, ecologistas, miembros de pastorales sociales y ciudadanos "a pie". 
Lo dicho anteriormente, contribuye a entender la gran cantidad de actos de protestas que se realizaron a lo largo del territorio nacional. Para estos efectos, el término "acto de protesta" reúne diversas formas de movilización y de demanda por parte de los sectores sociales: bloqueos de calles y carreteras, marchas, huelgas, paros y huelga de hambre, entre otros. Durante los 20 días que van del 16 de marzo -bloqueo de los campesinos- al 4 de abril -día del diálogo entre gobierno y sectores en lucha y último día de protestas- se puede ubicar la mayor intensidad de la lucha social. Un recuento conservador ${ }^{31}$ permite contabilizar 274 actos de protesta, ${ }^{32}$ lo que significó un promedio de 13.7 actos de protesta diarios, incluyendo los días en que no se registraron movilizaciones ( 25 de marzo, sábado 2 y domingo 3 de abril). Existieron días que sobrepasaron este promedio: durante el mes de marzo, este fue el caso de los días 17 (21 actos de protesta), 22 (40 actos), 23 (34 actos), 28 (17 actos) y 30 (91 actos); y en abril el día 3 (con 17 actos de protesta) (Gráfico 1).

Gráfico 1. Movimiento nacional en contra del "combo": Número total de paros, manifestaciones, bloqueos y otros actos de protesta,

16 de marzo al 4 de abril del 2000

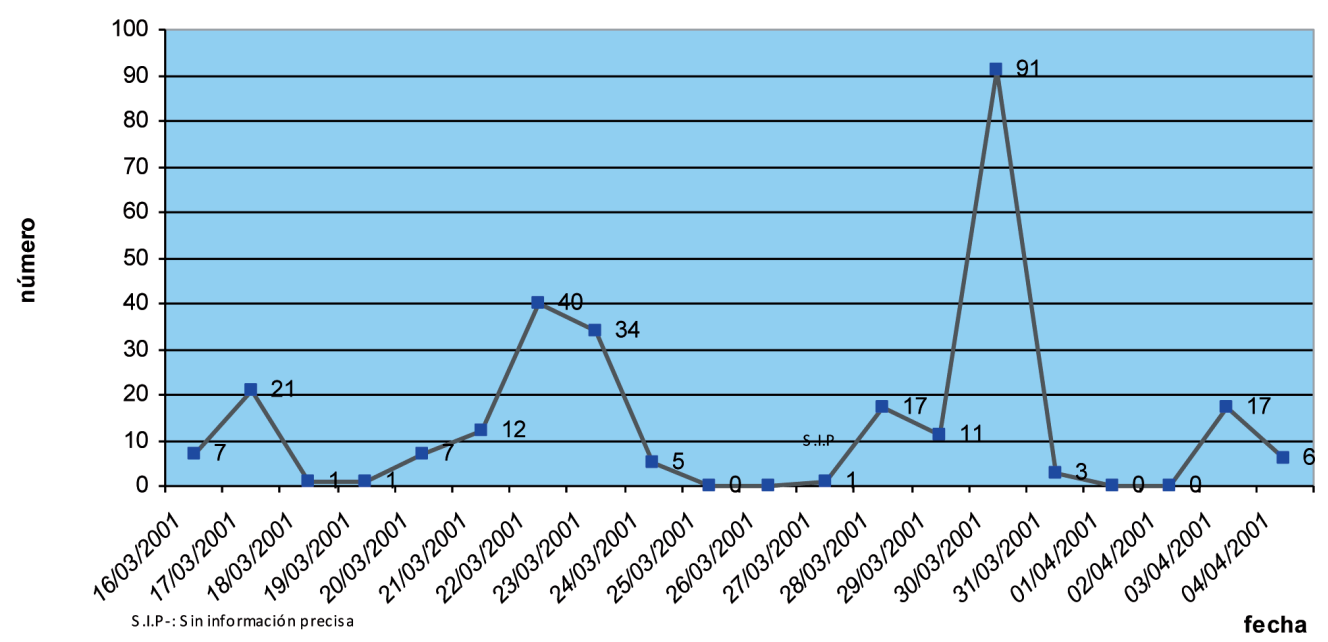

Figura 1. Movimiento nacional en contra el "combo".

Fuente: reconstrucción con base en la Nación Digital del 17 de marzo al 5 de abril del 2000

La escala del movimiento de lucha en contra del "combo" la marcó el movimiento campesino que la madrugada del 16 de marzo bloqueó vías en varios puntos del país: la carretera a Cartago en el Alto de Ochomogo, así como vías en Cañas, Guápiles, Pérez Zeledón, San Carlos y Limón. El día siguiente al bloqueo de los agricultores, el 17 de mayo, hubo al menos 21 actos de protesta (entre manifestaciones y bloqueos) en diferentes partes del territorio nacional. Uno de los puntos de estas movilizaciones fue el apoyo al sector campesino, además de la presión por el 
retiro del "combo", en el marco del anuncio hecho por la Asamblea Legislativa de su intención de aprobar el proyecto en primer debate, entre el lunes 20 y el martes 21 de marzo. ${ }^{33}$

El 20 de marzo, día de la aprobación en primer debate del Combo, se realizaron al menos 21 actos de protesta en todas las provincias. Uno de estos actos fue el inicio de una huelga de hambre por dos estudiantes de la Universidad Nacional y dos estudiantes del Instituto Tecnológico. ${ }^{34}$

Debe destacarse que en el mismo período que va del 16 de marzo al 4 de abril, los bloqueos de vías se constituyeron en un acto de protesta sumamente extendido; ha sido posible registrar un total de 103, lo que representa un $37.6 \%$ del total de actos de protesta. En algunos días los bloqueos llegaron a representar hasta el 100\% del total de actos de protesta registrados (16 y 27 de marzo) y en otros significaron una proporción muy importante (Gráfico 2). Esta forma de lucha marcó una diferencia sustantiva en comparación con movimientos anteriores de gran envergadura tales como el movimiento estudiantil de 1991 a favor del presupuesto de las Educación Superior Pública, y el de 1995 desarrollado por el magisterio y el Frente Cívico a raíz del Pacto Figueres-Calderón. En este último movimiento, el principal recurso utilizado por los sectores manifestantes fue el de las marchas, ${ }^{35}$ las cuales no tuvieron todas las repercusiones de los bloqueos, tales como los trastornos en el comercio, desabastecimiento de gasolina en ciertos momentos críticos del

Gráfico 2. Movimiento nacional en contra del "combo": Bloqueos de vías como porcentaje del total de acciones de protesta,

16 de marzo al 4 de abril del 2000

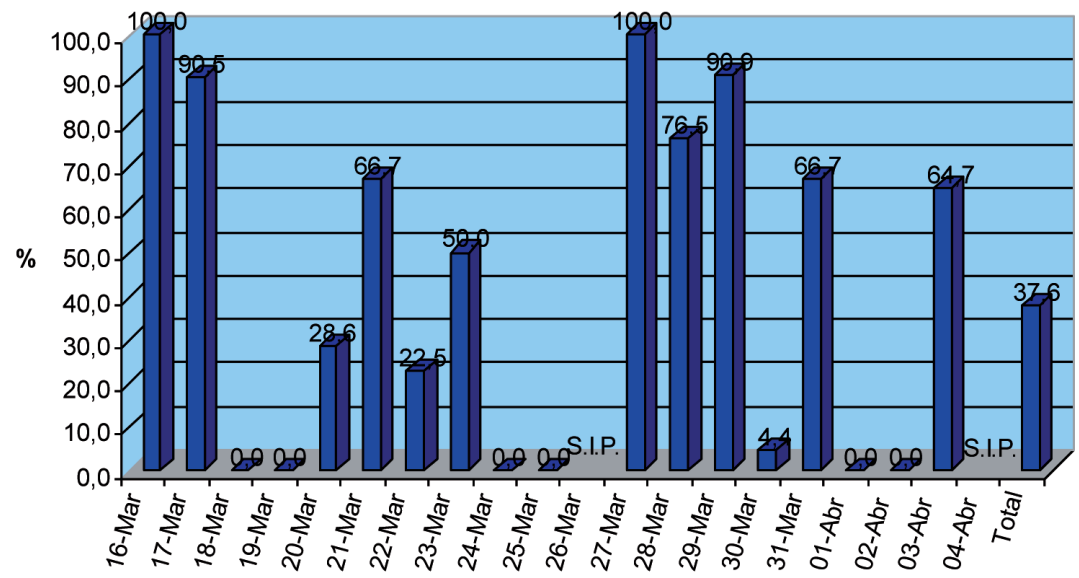

fecha

S.I.P.: Sin información precisa

Figura 2. Movimiento nacional en contra el "combo".

Fuente: reconstrucción con base en la Nación Digital del 17 de marzo al 5 de abril del 2000 
movimiento, trastornos viales, entre otros. Entre las vías más bloqueadas durante el período figuró la Carretera Interamericana -la cual fue cerrada repetidamente en distintos puntos del país- y la carretera San José a Cartago, significativa por encontrarse en esta vía una de las plantas más importantes de la Refinería Costarricense de Petróleo.

Los bloqueos significaron un aumento de las intervenciones por parte de la Fuerza Pública, también si se le compara con la movilización social de 1995. Si bien no se cuenta con información oficial sobre la cantidad de acciones policiales para el levantamiento de bloqueos, ha sido posible registrar al menos 15 eventos de este tipo por parte de la Fuerza Pública, ${ }^{36}$ que sin embargo no pudo dar abasto ante la magnitud de las movilizaciones.

Si bien existen múltiples actos que muestran la gran extensión y apoyo del movimiento durante el período, cabe resaltar dos de ellos. En primer lugar destaca la gran magnitud de la manifestación realizada en Casa Presidencial el día 23 de marzo, una de las movilizaciones más grandes vista en muchos años. Ésta mostró el masivo apoyo al movimiento y la capacidad de convocatoria de las organizaciones sociales. En segundo lugar, deben resaltarse los días 3 y 4 de abril, días en que el movimiento social convocó a huelga general. Es en el marco de esta movilización que, finalmente, el gobierno y los sectores sociales se sentaron a dialogar. En este proceso tuvo un importante papel la convocatoria de la Comisión Facilitadora del Diálogo, sobre la cual se profundiza adelante.

\section{La opinión pública frente al movimiento en contra del "combo"}

Uno de los elementos que más destacan en la coyuntura, es el gran respaldo que la ciudadanía le brindó al movimiento social en contra del "combo". En esta dirección, un $72 \%$ de la opinión pública mostró su acuerdo con las marchas. Incluso el 41,9\% de los que estaban a favor del plan señaló su acuerdo con ellas "lo cual muestra una importante legitimidad del derecho a protestar a través de ellas". Sin embargo, los bloqueos tuvieron un menor apoyo: un 42,6\% de las personas entrevistadas señaló estar de acuerdo y un 55,7\% estuvo en contra de éstos. Tomando en consideración únicamente a quienes están en desacuerdo con el combo, un 64,1\% brindó su apoyo a esta forma de protesta. ${ }^{37}$

Por otra parte, no deja de ser relevante que un $12.4 \%$ de las personas entrevistadas señalara haber participado directamente en las protestas que se realizaron antes del 25 de marzo. Aún más, entre las personas en desacuerdo con el combo y que no habían participado en las protestas, dos terceras partes manifestaron que participarían si tuvieran la oportunidad de hacerlo. ${ }^{38}$

Así pues, dos terceras partes de los costarricenses aprobaban en esta coyuntura las protestas nacionales (especialmente las personas de mayor nivel educativo), 
mientras que al otro tercio $(31,4 \%)$ le parecía mal que se hubieran producido. Por otra parte, para el $60 \%$ de los costarricenses no era aceptable protestar bloqueando las vías públicas (opinaban así principalmente los simpatizantes del PUSC), mientras que al 39\% le parecía aceptable. ${ }^{39}$ De esta suerte, aunque la lucha social y, más específicamente el derecho a protestar, gozaba de una considerable legitimidad social, lo cierto es que las opiniones distaban de ser homogéneas y, mucho menos, consensuales.

\section{Los actores políticos a favor del "combo"}

Efectivamente, durante esta coyuntura es posible observar una polarización de intereses entre los sectores sociales opuestos a la apertura del mercado de las telecomunicaciones y a la participación privada en el ICE, por una parte, y el gobierno, las fracciones parlamentarias del PUSC, el PLN y el empresariado, por la otra. Dentro de la Iglesia Católica, y a diferencia de otros sectores, Monseñor Román Arrieta avaló el proyecto antes del primer debate, argumentando que era apremiante modernizar el ICE, lo cual era distinto a privatizarlo. ${ }^{40}$ Con esta posición, Arrieta daba continuidad a su alianza con la clase gobernante que ya se había hecho patente desde el Pacto Figueres-Calderón. ${ }^{41}$ En el 2000, como en 1995, esta alianza parece haberse reforzado con algunos sectores de la prensa. El Periódico La Nación, según el análisis de Kattia Martín, “orientó sus fuerzas a mencionar la huelga a partir de términos negativos, (...) disminuyéndola siempre", y privilegiando las declaraciones de quienes se oponían a la huelga sin tomar el parecer de los manifestantes. ${ }^{42}$ Este conjunto de posiciones encontradas dio a esta coyuntura el carácter de lucha entre grandes conglomerados sociales.

Así pues, la participación del empresariado a favor de la aprobación fue cualquier cosa menos pasiva. Diversas instancias representantes de los intereses privados tales como la UCCAEP, la junta directiva de la Promotora de Comercio Exterior y las cámaras de Industria y de Comercio, expresaron su apoyo al Presidente, e instaron al Gobierno y a la Asamblea Legislativa a aprobar el "combo". La Cámara de Comercio Costarricense-Norteamericana, por ejemplo, mostró el apoyo al proyecto pidiendo contribuciones a sus asociados para cubrir los gastos necesarios con el fin de demostrar a los diputados el apoyo masivo que la iniciativa tenía en el sector privado. ${ }^{43}$

Otros sectores con intereses en el proyecto buscaron posicionar entre la opinión pública la importancia de la apertura. La Cámara de Productores de Software (CAPROSOFT), difundió una encuesta realizada entre las 50 compañías asociadas a dicha Cámara, señalando que el 100 por ciento consideraba que la apertura del mercado debía ser inmediata. Tanto CAPROSOFT como empresarios de radiolocalización tenían interés en la ruptura del monopolio de telecomunicaciones e Internet. ${ }^{44} \mathrm{La}$ Cámara Nacional de Radio (CANARA), por otro lado, impulsó la aprobación del 
"combo", con un interés particular en el capítulo de las telecomunicaciones pues aportaría "ganancias tanto al público como a las empresas nacionales". ${ }^{45}$

El empresariado buscó hacer efectiva la aprobación de la reforma, apelando al orden social y tratando de contrapesar la enorme beligerancia que adquirió la lucha social en contra de la reforma. En este sentido varias Cámaras desplegaron un discurso conservador e hicieron un llamado al respeto del sistema político y de representatividad. En este sentido, el entonces presidente de la Cámara de Industrias, Marco Vinicio Ruiz, exhortó a los ciudadanos a defender las estructuras democráticas, el gobierno y la Asamblea Legislativa, evitando seguir a quienes deseaban generar el caos y cuestionar la institucionalidad; al tiempo que el primer vicepresidente de la Unión Costarricense de Cámaras y Asociaciones de la Empresa Privada (UCCAEP), llamaba a respetar el sistema de delegación en los diputados. ${ }^{46}$

Además del Gobierno y de las fracciones parlamentarias de mayoría, es posible identificar otros sectores que apoyaron la aprobación del Combo. Los expresidentes Oscar Arias Sánchez y José María Figueres, así como los precandidatos de Liberación Nacional, Antonio Álvarez, Rolando Araya y José Miguel Corrales, realizaron diversas manifestaciones de apoyo al proyecto. Corrales, sin embargo, se pronunció posteriormente para que los diputados de la fracción liberacionista no votaran a favor del combo en primer debate. ${ }^{47}$

El cambio de la posición de Corrales, posiblemente hacía ver un cálculo político en una parte del Liberacionismo. Aproximadamente diez días después de aprobado el proyecto, una parte de la fracción parlamentaria de aquel partido también modificó su posición y decía "a los compañeros de gobierno que permitan abrir un diálogo con los demás sectores para, o mejorar la ley, o cambiar aspectos que algunos sectores consideran que deberían de cambiarse", abriendo la posibilidad de incluir esas modificaciones por medio de la ley complementaria ${ }^{48}$ En conferencia de prensa del viernes 24 de marzo, la dirigencia de Liberación Nacional, señaló que la marcha ciudadana del jueves 23 de marzo en contra del "Combo ICE", incidió en que el partido considerara no votar el proyecto en segundo debate "hasta que el pueblo de Costa Rica no esté completamente confiado y tranquilo de que es un proyecto que beneficia a todos los costarricenses". ${ }^{49}$ Aunque la diputada liberacionista Sonia Picado, seguía sosteniendo que no se retrocedería en la aprobación de la Ley, era claro que la lucha que los opositores a la reforma desarrollaban en las calles, comenzaba a dividir a sus adversarios. Aún así, la lucha debía pasar por otros nuevos momentos.

\section{La estrategia gubernamental ante el movimiento en contra del "combo"}

Patricia Alvarenga ha señalado que durante la movilización contra el "combo", una de las estrategias del gobierno fue presentarse como "ente superior que puede asegurar que sus oponentes sencillamente están equivocados". Por lo 
tanto el Estado se colocó en el papel de educador para pacificar a los "equivocados ciudadanos" ${ }^{50}$ En los momentos más álgidos del conflicto, el gobierno desarrolló una campaña por los medios de comunicación encaminada a mostrar la conveniencia del "combo". Sin embargo, una encuesta sobre el tema, realizada por los Institutos de Investigaciones Sociales y Psicológicas de la UCR, mostró la poca eficacia de la propaganda gubernamental durante la coyuntura. ${ }^{51}$ Efectivamente, sólo un $9.8 \%$ de las personas entrevistadas expresó que la publicidad del gobierno le hizo cambiar de opinión, de las cuales sólo un $15.6 \%$ expresó que había pasado de estar en contra a estar de acuerdo con el Combo y un 2.2\% de ser imparcial a estar a favor; por otro lado un $15.6 \%$ pasó de estar de acuerdo a estar en contra; finalmente a un $13.3 \%$ se le reforzó su posición a favor del "combo" y a un $28.9 \%$ se le reforzó su posición en contra.

Si bien esta pretensión de superioridad adoctrinadora fue una constante en todo el período del conflicto, podríamos agregar otros momentos de la estrategia gubernamental. Quizá una de las primeras estrategias de desactivación, fue la de una supuesta apertura al diálogo. En el mes de enero de 2000, antes de iniciar el trabajo de la Asamblea Legislativa, el Poder Ejecutivo propició un acercamiento con sindicatos del ICE, cooperativas, ambientalistas, empresas municipales eléctricas y diputados; lo cual respondía, según Eliseo Vargas, al deseo del Gobierno de dialogar para escuchar sugerencias de estos sectores acerca del "combo energético". ${ }^{52}$ Como podrá apreciarse, era claro que estos sectores políticos, supuestamente legitimados por su calidad de representantes democráticamente electos, se atribuían a sí mismos la capacidad de decidir unilateralmente el rumbo de la reforma. A los diferentes sectores sociales mencionados sólo les correspondía realizar "sugerencias" que, a juzgar por la posterior postura gubernamental, distaban de ser vinculantes.

Ya iniciada la protesta, el gobierno volvió a utilizar el eslogan del diálogo para propiciar la desmovilización. Aunque éste pretendía ser un diálogo ya no sectorial, sino nacional, no se alejaba de los mismos supuestos del que anunciara Eliseo Vargas un poco tiempo antes. Ahora, Rodríguez decía que se aprovecharía el mes de marzo "para dar todas las explicaciones, oír todas las observaciones y tener todos los diálogos que sean necesarios". ${ }^{53}$ Para ello, el Presidente de la República solicitó a la Asamblea Legislativa abrir un espacio para escuchar propuestas acerca de la Ley y anunció que a partir del 29 de marzo, y durante 10 días, se abriría una oficina dedicada a recibir propuestas sobre el tema. Los sectores en pugna no tardaron en reaccionar. El coordinador del Frente Interno del ICE, Jorge Arguedas, argumentó que no era posible incluir todas las modificaciones en este período y se desconfiaba de la eficacia de la propuesta. ${ }^{54}$ La fuerte oposición a las fórmulas propuestas por el Ejecutivo para canalizar el descontento, así como la gran extensión del movimiento, llevaba a la necesidad de ensayar mecanismos de diálogos alternativos. 
Es evidente que, en esta concepción, a los sectores populares y medios no les correspondía trazar el rumbo del país. De manera aguda, Alvarenga ha anotado que, durante la lucha contra el "combo", el término de "clase política" condensó la sensación de distanciamiento producida entre los agentes conductores del Estado y la sociedad civil debido a la "violenta capacidad de tomar decisiones políticas" a sus espaldas "y, en particular, de enriquecerse con el lucro de los bienes públicos". ${ }^{55}$

A esta sensación hay que agregar la convicción de los propios políticos sobre su legitimidad para superponerse al criterio de la ciudadanía. La cúpula gubernamental reafirmó esta certeza, amparada en el sistema político representativo. Ello podría ejemplificarse cuando Miguel Ángel Rodríguez anunció medidas represivas contra los funcionarios públicos sumados a las protestas, planteando que no solamente se encontraba en juego el ICE sino el sistema de toma de decisiones y el orden público: "cuando 45 diputados a favor y 10 en contra aprueban algo y alguien cree que tiene el derecho de decir que se tiene que hacer lo que él quiere, entonces tenemos una subversión". ${ }^{56}$ Lo que no consideraba este discurso era que los insurrectos eran los ciudadanos que brindaban legitimidad a las elecciones legislativas y presidenciales.

En este proceso de distanciamiento, el gobierno esgrimió, desde muy temprano en el 2000, otro argumento en contra de la ciudadanía opositora al "combo": el de su manipulabilidad. En la perspectiva gubernamental, sin duda alguna, se trataba de una manipulación hacia el lado incorrecto, hacia el rechazo de la reforma. Así, a inicios de aquel año, el gobierno proponía que el "diálogo" debía ser sectorial y no nacional; el entonces Presidente Ejecutivo del ICE, Rafael Sequeira, señaló que no tenía ningún sentido someter la apertura de las telecomunicaciones y energía a una consulta popular, ya que las consultas podían ser manipuladas. ${ }^{57}$ Era claro que el gobierno y sus aliados no querían jugarse la carta del referéndum en las urnas, ante una muy posible derrota. Tuvieron que presenciar, entonces, el referéndum de las calles.

Como era de esperar, una vez que iniciaron las protestas en contra del "combo", el gobierno tampoco reconoció la legitimidad de la lucha social ni de las motivaciones de quienes la impulsaban. El Presidente de la República, Miguel Ángel Rodríguez, sacó a colación el deslucido eslogan de la Guerra Fría, sobre la existencia de agitadores que "con otros intereses quieren perturbar la tranquilidad". ${ }^{58} \mathrm{Al}$ tiempo, el ministro de la Presidencia, Danilo Chaverri, restaba importancia a las marchas pues, según decía, más de la mitad de los participantes eran estudiantes de secundaria; ${ }^{59}$ lo cual, desde su perspectiva, restaba mérito a la movilización. En ambos argumentos subyacía el argumento de la manipulabilidad de los equivocados ciudadanos y la invalidez de los intereses de los no-ciudadanos: los más jóvenes. Muy posiblemente esta inventiva ideológica del gobierno reafirmó la pérdida de credibilidad de los políticos entre la ciudadanía. 
Continuamente desbordado por los acontecimientos, el Gobierno reconoció en cierto momento el derecho de protestar advirtiendo, sin embargo, que no toleraría excesos. Así fue que, a partir del bloqueo de los campesinos en Ochomogo, conformó un "comando anti-crisis" integrado por funcionarios de diversas instituciones públicas con sede en el Ministerio de Seguridad Pública. Esta instancia tuvo el cometido de diseñar y supervisar las acciones de vigilancia de las zonas de conflicto y levantar bloqueos. ${ }^{60}$ El Presidente sostuvo que resultaba peligroso permitir que los bloqueos paralizaran el libre acceso por el país. Se hacía patente la preocupación de que el movimiento se saliera de su control, lo que produciría "una ingobernabilidad total" ${ }^{61}$ Lo cierto es que en esta corta coyuntura, Rodríguez debía de compartir con la ciudadanía opositora la conducción del país, misma que lo obligaba a sentarse a negociar el rumbo inmediato de los asuntos nacionales.

\section{Polarización social y las dificultades para el diálogo}

Las propuestas de negociación para salir del conflicto comenzaron a surgir unos días después de la aprobación del "combo" en el contexto de profundas desconfianzas entre las partes, y de divisiones dentro de los mismos sectores que se oponían a la reforma del ICE. El sábado 25 de marzo, el presidente Rodríguez anunció que consideraba adecuada una propuesta hecha por la Asociación Nacional de Educadores (ANDE) y la Asociación de Profesores de Segunda Enseñanza (APSE), que consistía en la conformación de una "comisión de notables" para iniciar el diálogo. Según la propuesta, tal comisión estaría compuesta por el ex-vicepresidente de la República Jorge Manuel Dengo; el obispo de Limón, Francisco Ulloa, y el rector de la Universidad Nacional, Jorge Mora. Éstos tendrían la función de recoger las inquietudes populares y reunir en un documento aquellas que tuviesen una posición de consenso y viabilidad. Estos sectores del magisterio solicitaron al Presidente comprometerse a no aprobar el "combo" en tanto no se aclarasen las dudas y fueran incorporados en la legislación los planteamientos populares.

No obstante, la magnitud de la movilización de los opositores a la reforma hacía inviable que un asunto de tanta repercusión quedara en manos de unos pocos. Algunos de los dirigentes del movimiento opositor al "combo", entre ellos Jorge Arguedas (ICE) y Albino Vargas (ANEP), se manifestaron en contra de las características de la propuesta, considerándola como una maniobra para romper el movimiento de protestas contra el plan; ${ }^{62} \mathrm{y}$, al igual que los otros sectores populares, sostuvieron la necesidad de mantener la presión y rechazar cualquier posibilidad de negociación con el gobierno mientras no se retirara el proyecto de la corriente legislativa. ${ }^{63}$

Al mismo tiempo que la propuesta era hecha pública en conferencia de prensa, afloraron diferencias dentro del magisterio nacional. Una parte de éste buscó bajar la creciente intensidad que adquiría la lucha social de oposición. El presidente de 
la Asociación Nacional de Educadores (ANDE), llamó a maestros, profesores, estudiantes y funcionarios a regularizar el trabajo a partir del lunes 27 de marzo. ${ }^{64}$ A diferencia de ANDE y APSE, el Sindicato de Educadores Costarricenses (SEC) y el Sindicato Patriótico de la Educación (SINPAE) realizaron un llamado a los educadores y a la ciudadanía a luchar contra la aprobación del "combo" y pidieron al gobierno realizar un plebiscito. Dentro de la misma ANDE, algunos sectores de las bases mostraron un fuerte rechazo a los lineamientos de la dirigencia de su organización. ${ }^{65}$

La dificultad de encontrar puntos de confluencia hacía prever, por otra parte, la dificultad de llegar en lo inmediato a una salida negociada al conflicto. Sin embargo, durante la semana del 27 de marzo al 2 de abril, la búsqueda de mecanismos para el acercamiento entre el Gobierno y los sectores opositores al Combo se intensificó. La Federación de Trabajadores de Limón (FETRAL), propuso establecer una mesa de conversaciones. La propuesta tenía la ventaja de estar limitada a la apertura de un espacio para el diálogo sin condiciones previas para ninguna de las partes. Se establecía una mesa facilitadora que estaría conducida por el rector de la Universidad de Costa Rica, Gabriel Macaya; el obispo de Limón, monseñor Francisco Ulloa, y la defensora de los habitantes, Sandra Piszk. El Rector Gabriel Macaya señaló su intención de aceptar, siempre y cuando participaran los rectores de las otras universidades públicas. Esta propuesta difería sustancialmente de la hecha por ANDE y APSE, pues no sería un grupo de personas de gran prestigio las que introducirían modificaciones al proyecto. Más bien, éstas tendrían como cometido propiciar las condiciones adecuadas para dialogar. Para impulsar esta propuesta, el lunes 27 de marzo, dirigentes de la FETRAL se reunieron con el mandatario Rodríguez en la Casa Presidencial. La fuerza y beligerancia de la FETRAL en Limón y su capacidad de paralizar puntos clave de la economía, la convertían en una interlocutora fundamental.

En este contexto, la dirigencia de la Asociación de Empleados del ICE, reiteró que las negociaciones iniciarían únicamente cuando el Gobierno retirase el proyecto de la Asamblea Legislativa; mientras que el ministro de la Presidencia, Danilo Chaverri, insistía en que lo procedente era continuar el trámite del proyecto de ley, recoger aquellas propuestas que fuesen razonables y tramitarlas por medio de un plan paralelo. El Ministro señaló, no obstante, la voluntad del gobierno a dialogar. ${ }^{66}$

Como se ha anotado, la fracción legislativa del PLN tomó distancia de la posición gubernamental en contra de la protesta y ejerció presión sobre el Ejecutivo para que iniciara el diálogo. Liberación no votaría el plan en segundo debate -programado para el miércoles 29 de marzo- mientras que el Gobierno no restableciera la calma social del país y dialogara con los grupos opuestos a la aprobación del Combo y expresó su intención de no sesionar hasta entonces. ${ }^{67}$ 
En el contexto de búsqueda de acercamientos para el diálogo, el Sindicato de Empleados de la Universidad de Costa Rica (SINDEU) anunció el 28 de marzo, la preparación de una "huelga general de brazos caídos" por parte de organizaciones sindicales, comunales, estudiantiles, ambientalistas y comités cívicos, que hacía alusión a los hechos previos al estallido de la guerra civil de 1948. Este uso de la memoria de los acontecimientos previos al 48 tenía clara intencionalidad de presionar al gobierno con una mayor agudización del conflicto, si bien la coyuntura del 2000 no tenía las mismas características ni proporciones con lo sucedido entonces. Aquella huelga, realizada en julio de 1947, había sido convocada por los opositores a la alianza caldero-comunista, y era más bien un paro patronal que se concretó en un cierre de negocios. Ciertamente la conflictividad se agudizó luego con la llegada de trabajadores que los comunistas y el gobierno trajeron del Caribe y del Pacífico Central. ${ }^{68}$ En el 2000, en un contexto completamente distinto, el recurso a aquella memoria ciertamente parecía querer evidenciar la gran polarización del nuevo momento. La huelga general se efectuaría la semana que comenzaba el 3 de abril, en el caso de que el Presidente Rodríguez no retirase de la Asamblea Legislativa el "combo". La misma Federación de Trabajadores Limonenses (FETRAL), que impulsara la propuesta de diálogo, convocó a una huelga indefinida en la provincia de Limón a partir del mismo lunes 3 de abril. ${ }^{69}$ El país ya se encontraba en gran medida paralizado por las protestas y la huelga profundizaba aún más esta situación. El movimiento anti-reforma apostaba todas sus cartas para retirar el "combo" de la corriente legislativa.

\section{Los acuerdos: la búsqueda de puntos de encuentro}

En el transcurso de la semana del 27 de marzo, logró conformarse una comisión facilitadora para el diálogo, compuesta finalmente por los cuatro Rectores de las Universidades Públicas, la Defensora de los Habitantes, Sandra Pisk, y un representante de la Iglesia Católica. Esta comisión realizó una convocatoria al gobierno y a los sectores en lucha, para reunirse el lunes 3 de abril. Sin embargo, los grupos opositores al "combo" solicitaron a la comisión aplazar por 24 horas la reunión, señalando que sus esfuerzos se abocarían a la organización y coordinación del paro nacional decretado para ese día. Para la reunión en que se efectuaría el diálogo, fechada ahora para el 4 de abril, Jorge Arguedas, coordinador del Frente Interno de Trabajadores del ICE, reiteró que insistirían en el retiro del plan del ICE del plenario legislativo, mientras que el ministro de la Presidencia, confirmaba la asistencia de la delegación gubernamental a la cita que había sugerido la comisión facilitadora para el lunes 3. Esta comisión se declaró en sesión permanente y apeló a la buena voluntad de las partes..$^{70}$

El lunes 3 de abril, múltiples puntos del país fueron bloqueados, lo que mostró un mayor grado de organización de los diferentes sectores en lucha y una importante 
respuesta de los opositores al "combo" a la convocatoria realizada por los gremios. Más que la legitimidad de los sindicatos por sí mismos, esta respuesta de la ciudadanía evidenció la consolidación de una alianza en torno al ICE y sus significados, como se ha analizado más arriba. La amplia difusión de esta alianza se expresó en múltiples acciones de protesta en diferentes puntos del país: fueron paralizadas las actividades en los muelles de Limón y Caldera durante prácticamente todo el día, y se realizaron bloqueos en Ochomogo, San Pedro y Limón con enfrentamientos entre la Fuerza Pública y las personas manifestantes. Estudiantes de la Universidad de Costa Rica (UCR), la Universidad Nacional (UNA) y del Instituto Tecnológico de Costa Rica (ITECR) bloquearon la rotonda de la Hispanidad, en Montes de Oca, la vía frente a la UNA, en Heredia y la autopista Florencio del Castillo, en el Alto de Ochomogo. Otros bloqueos se realizaron durante todo el día en la carretera Interamericana Norte, en Liberia y en Cañas, así como en Pérez Zeledón, San Vito de Coto Brus, Guápiles, Siquirres y la entrada a la ciudad de Puntarenas. ${ }^{71}$ Los habitantes se apropiaron de su país con el fin de inclinar la balanza de las negociaciones a favor de una institucionalidad con un carácter social.

Las protestas impulsadas por el movimiento opositor al combo tuvieron un enorme impacto sobre la economía del país, las cuales sin duda no podían pasar desapercibidas para la clase política. Las protestas paralizaron la distribución de hidrocarburos durante todo el día 4 de abril, debido a la huelga de trabajadores de RECOPE, lo cual terminó de influir en la situación de desabastecimiento que se venía presentando desde el sábado 1 de abril en todo el país. Se trataba, en todo caso, de un costo que gran parte de los habitantes estaban dispuestos a asumir, así como el costo de desplazarse caminando largos trechos hacia sus trabajos, tan temprano como cuando los campesinos bloquearan Ochomogo al inicio del movimiento. Las protestas también afectaron el sistema de telecomunicaciones, reportándose a la altura del 4 de abril, aproximadamente 10.000 averías acumuladas. El cierre de los muelles de Caldera y Moín generó cuantiosas pérdidas. Sólo en este último caso, la pérdida del día 4 de abril ascendió a 500.000 cajas de banano valoradas en unos US\$2 millones (más de $₫ 600$ millones en el momento) y de unas 100.000 cajas de piña y melón con un costo estimado de $\$ 500.000$ (más de $\not 150$ millones del momento)..$^{72}$ Entre el lunes 3 y el martes 4 han podido registrarse al menos 23 actos de protesta en diversos lugares el país, de los cuales aproximadamente la mitad fueron bloqueos (Gráfico 2).

En horas de la mañana del martes 4 de abril, con la complejidad del telón de fondo, y ante un Tribunal Supremo de Elecciones rodeado por manifestantes opositores al "combo", inició el diálogo entre el Gobierno, el empresariado y los sectores sociales. "Sectores sociales" se definieron los representantes de una parte de esta gran diversidad opositora. Sin duda alguna buscaba hacer una diferencia tajante con los sectores políticos y empresariales gobernantes, posicionados a favor del combo. 
Dentro de la comisión facilitadora del diálogo se encontraban los cuatro Rectores de las Universidades Públicas Gabriel Macaya (UCR), Jorge Mora (UNA), Alejandro Cruz (ITCR), Rodrigo Arias (UNED); la Defensora de los Habitantes, Sandra Pisk y Monseñor Francisco Ulloa por la Iglesia Católica.

Aún con las dificultades precedentes, este proceso de negociación posee una serie de características que pueden ser consideradas como hechos de gran relevancia en la vida democrática del país y que, a la larga, podrían ser ejemplificantes. En primer lugar, la expectativa que existía entre la ciudadanía sobre el desenlace del movimiento social se vio canalizada con la propuesta de los sectores sociales de transmitir televisiva y radialmente el encuentro en su totalidad. ${ }^{73}$ Esto fue efectivamente realizado por Canal 13 y por Radio Nacional, instancias de carácter estatal. Se creó, de esta manera, un foro abierto en el cual la ciudadanía podía darle seguimiento al diálogo y evaluar por sí misma una eventual salida al conflicto. Esta necesidad tenía como antecedente la enorme desconfianza de la población en las medidas gubernamentales que contribuyeron a dar grandes dimensiones a la lucha social. Posiblemente también incidió la tradición de cierta dirigencia de negociar independientemente de lo que dictaran sus propias organizaciones. También representó la voluntad de las partes por ser evaluadas por la opinión pública. Esta situación parece ser un hecho inédito en la procura de una mayor transparencia de los procesos de negociación.

Un segundo hecho relevante lo representa el establecimiento de una mesa facilitadora del diálogo formada por personas con cierta legitimidad social. Ésta persiguió proporcionar las condiciones óptimas para que las partes en conflicto iniciaran el diálogo sin condiciones previas. Dadas las dimensiones y características que cobró el conflicto, este factor permitió el acercamiento definitivo.

Un tercer hecho relevante de las negociaciones fue la voluntad de las partes de encontrar una salida negociada al conflicto. Esto implicó la búsqueda puntos de acercamiento, así como ceder en ciertos aspectos. Ejemplo de ello fue que el representante empresarial y presidente de la Unión Costarricense de Cámaras y Asociaciones de la Empresa Privada (UCCAEP) fue quien propuso, en primera instancia, la integración de una comisión mixta compuesta por el gobierno, empresarios y los sectores sociales. Esta comisión tendría el cometido de incluir todas las observaciones que surgieran sobre el tema. A su vez, el jefe de la fracción del PUSC, propuso la suspensión del trámite de la ley por el tiempo necesario para que se incorporaran las sugerencias y cambios promovidos. Ello sirvió como punto medio a la posición de los sectores sociales, quienes sostenían que el plan debía ser retirado del trámite legislativo como condición básica para sentarse a negociar. Por su parte, el presidente del Congreso propuso que la comisión mixta estuviese al amparo de la Asamblea Legislativa para que sus resultados fueran vinculantes, por lo que el acuerdo firmado en el Tribunal Supremo de Elecciones puso de manifiesto lo que se cita en el recuadro 1. 


\section{RECUADRO 1}

\section{El acuerdo firmado en el Tribunal Supremo de Elecciones}

a) "Integrar una Comisión Especial Mixta compuesta por 9 diputados, tres representantes del Frente Interno de Trabajadores del ICE, un representante de las federaciones de estudiantes universitarios, un representante de las organizaciones ambientalistas, dos representantes de los grupos de pastoral social de la Iglesia, un representante de los empresarios y un representantes del Poder Ejecutivo, a efecto que atiendan, reciban, sistematicen e introduzcan las alternativas que se aprueben como producto de las proposiciones de los diferentes sectores de la sociedad costarricense e informen al Plenario Legislativo del resultado de su labor a efecto de que en esta instancia mediante el trámite parlamentario de rigor, se pronuncie".

b) "Retirar del trámite, mediante procedimiento reglamentario previsto, el Proyecto de Mejoramiento de lo Servicios Públicos de Energía y Telecomunicaciones y de la Participación del Estado, expediente 13.873, por un plazo de hasta 150 días, prorrogables lo que sea necesario de acuerdo al avance del trabajo de la Comisión, para la elaboración e introducción de las iniciativas acordadas"

c) "Para garantizar que las iniciativas de la Comisión Especial Mixta que se integra en el inciso a) anterior tengan eficacia legislativa se concede a esta misma Comisión la potestad de determinar la vía reglamentaria más indicada al efecto de dictaminar. Dicho dictamen debe procurarse sea por consenso de los sectores representados; en su defecto, se procederá en aplicación del Reglamento de la Asamblea Legislativa"

d) "El Gobierno y las fracciones legislativas se comprometen solemnemente ante esta instancia de diálogo y la sociedad costarricense, a tramitar, de manera exclusiva en el plenario legislativo y en relación al ICE, el resultado de la Comisión Mixta, vía artículo 154 del Reglamento de la Asamblea Legislativa, y a no dar trámite a ningún proyecto de ley con relación al ICE hasta tanto la Comisión Mixta no dictamine".

e) "El Gobierno se compromete en este acto a no proceder con ningún tipo de represalias, sanciones, rebajas salariales, ni presentará o continuará acciones penales y civiles, así como tampoco cualquier otro tipo de medida similar contra los trabajadores y trabajadoras, estudiantes, organizaciones y ciudadanos que han participado en esta jornada. De igual forma el Gobierno girará instrucciones en este sentido a las Instituciones Autónomas y Empresas Públicas correspondientes".

f) "La Comisión Facilitadora será garante de la correcta aplicación del proceso anterior señalado. Velará específicamente por que el trabajo de la Comisión Especial Mixta se dé en el plazo establecido en el punto b) anterior".

g) "Los sectores acuerdan en este acto levantar inmediatamente las medidas de fuerza que atenten contra los derechos de los demás ciudadanos, así como suspender la propaganda alusiva al tema".

h) Dar a conocer este acuerdo a los medios de comunicación

Fuente: Texto del acuerdo (Foro de La Nación, 6/4/2000, p. 14 A.) 
Como reseñara un periodista "la postergación en el trámite legislativo del plan abrió la puerta a la salida de la crisis" ${ }^{74} \mathrm{~A}$ lo dicho debe sumarse la posibilidad de participación de la sociedad civil en el proceso de toma de decisiones. La necesidad de ceder ante las peticiones de la otra parte, abrió también la posibilidad de llegar a acuerdos sobre la composición de la comisión mixta, en la que cada actor tuvo que reconocer la representatividad del otro si se quería avanzar.

La conformación misma de una Comisión Legislativa con participación de representantes sociales, es un hecho relevante que muestra la posibilidad de innovar mecanismos de representación democrática. Ello fue el resultado de veinte intensos días de extendida participación de las y los habitantes buscando hacerse parte del gobierno del país en esta coyuntura. Habría que resaltar que dos terceras partes de la ciudadanía percibieron que la creación de la "comisión mixta" era una salida conveniente al conflicto para el país y sus instituciones, y una forma adecuada de atender las demandas ${ }^{75}$ Ello significó un importante aval a los resultados del proceso de negociación y mostró que las condiciones del diálogo generaron una confianza suficiente. Debe tenerse en cuenta, no obstante, que prácticamente la mitad de la población (49\%) no se sentía representada por la "comisión mixta", mientras que otra parte (43\%) si lo estaba. Como se discute más adelante, este panorama mostró que ameritaba la construcción de canales de efectiva participación del conjunto de la ciudadanía. ${ }^{76}$ No solo se trataba de la necesidad de un referéndum en las calles sino uno más formalizado.

En todo caso, la prudencia que caracterizó el diálogo es un quinto hecho relevante que evitó que el conflicto entorpeciera el diálogo y desembocara en una mayor magnitud del conflicto. Ejemplo de ello fue que, a las 11:40 a. m. del 4 de abril, Jorge Arguedas, coordinador del movimiento de protesta y vocero en la mesa de diálogo, denunció que en Cañas, Guanacaste, y en Puerto Limón, la policía forcejeó con los manifestantes. Ante esta situación, la comisión facilitadora del diálogo, solicitó la intervención del ministro de la Presidencia. Algunos minutos después, este ministro anunció el retiro de la policía de las zonas de protesta, a la vez que los sectores sociales se comprometieron a permitir el paso en forma intermitente en los diversos bloqueos. Ello dio pie al reinicio del diálogo, que culminó con la firma de un documento de acuerdo entre las partes a las 00:07 horas del 5 de abril. ${ }^{77}$ Se cerraba así uno de los capítulos más importantes en las luchas sociales en contra de las medidas de corte neoliberal. Alrededor del $60 \%$ de la opinión pública consideraba que el principal perdedor había sido el gobierno y que los máximos ganadores del proceso habían sido el pueblo, el país y los trabajadores. ${ }^{78}$ 


\section{¿QUÉ PASÓ DESPUÉS DE LA LUCHA?}

\section{La valoración de la opinión pública al respecto de los actores}

En un balance de lo sucedido con posterioridad a la lucha en contra del "combo", resulta interesante conocer la manera en que la población valoró el papel de los diferentes actores. Este es un aspecto de gran importancia pues buena parte de los habitantes del país, lejos de ser asépticos, tuvieron que ver en la coyuntura, de una u otra manera.

Desde esta perspectiva, no es poco significativo el difundido apoyo al movimiento opositor al "combo", según una encuesta de la Escuela y la Maestría de Ciencias Políticas realizada en abril de 2000. ${ }^{79}$ Según los resultados del estudio, en una escala de 0 a 10 los actores que tuvieron una mejor valoración fueron las Universidades Estatales y la Defensoría de los Habitantes $(7,7)$. Como se ha señalado, buena parte de las universidades, no sólo contribuyeron al proceso de negociación -participación que posiblemente le dio una alta nota a la Defensoría-, sino que tuvieron un papel en contra del "combo. Otros actores anti-combo tuvieron una valoración no tan alejada a la de las Universidades y la Defensoría; tal fue el caso de las y los estudiantes universitarios $(7,5)$, los Curas de San Isidro del General $(7,2)$ y los Sindicatos del ICE $(7,1)$. También alta, y muy similar a la de las Universidades y la Defensoría, es la calificación de los medios de comunicación $(7,6)$. Esta percepción es muy similar a la detectada por una casa encuestadora, que hacía notar que en el grupo con mayor aprobación entre la ciudadanía "se encuentran principalmente los sectores en protesta, los medios de comunicación y ningún representante de la clase política" ${ }^{80} \mathrm{Si}$ bien no se especificaba de qué medios de comunicación se trataba, la percepción más favorable que la población tenía hacia éstos resultaba paradójica pues, salvo ciertas excepciones como la del Semanario Universidad, las grandes empresas de la prensa impresa y radial parecieron respaldar a la clase política.

En ambas encuestas citadas, un grupo de aprobación intermedia estuvo conformado por los diputados Merino del Río y Otto Guevara, así como el partido Fuerza Democrática. Las valoraciones más desfavorables las obtuvieron el Gobierno, el PUSC, la Asamblea Legislativa, el PLN, la Fuerza Pública -que reprimió en diversas ocasiones a los opositores- y Carlos Vargas Pagán, entonces presidente de la Asamblea Legislativa. Fue precisamente en este último espacio, que el "combo" recibió su última estocada.

\section{Una estocada final para el "combo": la Sala IV y la declaración de inconstitucionalidad}

La aplicación de la vía rápida ${ }^{81}$ al proyecto del "combo", que tenía el propósito de aprobarlo "a golpe de tambor", como se solía decir en el momento, fue uno 
de los tantos indicadores que muestran la intención de la clase política por evadir la consulta democrática y por minimizar la capacidad de respuesta de los opositores. Más temprano que tarde, algunos políticos pagaron el precio con un alto desgaste político. El entonces presidente de la Asamblea, Carlos Vargas Pagán, quien se rumoraba era "presidenciable", agotó sus cartas políticas. Al presidente de la República, Miguel Ángel Rodríguez, le fue imposible realizar reformas significativas en lo que quedaba de su gobierno, entre ellas la apertura de los seguros. Debido a la menor legitimidad del Instituto Nacional de Seguros, muy probablemente otro habría sido el desenlace.

Pero la aplicación de la vía rápida al "combo", como mostró la declaratoria de inconstitucionalidad emitida por la Sala IV, mostró el poco aprecio de la clase política a las mismas reglas democráticas que decía defender. El 18 de abril del 2000, catorce días después de los acuerdos, la Sala declaró inconstitucional el "combo energético" por considerar que la Asamblea Legislativa había incurrido en violación de normas, principios y valores constitucionales..$^{82}$

Entre los principales puntos objetados por dicha Sala se encuentran cuatro. En primer lugar, el Decreto de convocatoria a sesiones extraordinarias había consignado al "combo" un número de expediente que no existía a la fecha de su emisión. Ello implicaba, a juicio de la Sala, un vicio de constitucionalidad. En segundo lugar, la Sala señalaba que el plazo de dos días es una garantía mínima de publicidad de los dictámenes con el fin de garantizar el conocimiento pleno y efectivo del mismo por los diputados. El plazo de dos días era del mayor interés público, por lo que resultaba irrenunciable y, como tal, debía ser aplicado con el mayor rigor. Su inobservancia era considerada una violación sustancial al procedimiento y su infracción revestía una gran gravedad. Este era el caso del "combo", cuyo dictamen había sido puesto en la red parlamentaria a altas horas de la noche, cuando la mayoría de los diputados no se encontraban en sus oficinas. En tercer lugar, la Sala consideraba que había existido un exceso de facultad de enmienda por parte de los diputados en el caso de un texto que era altamente innovador. Ello producía la inconstitucionalidad de las adiciones realizadas. Finalmente, el rechazo de una serie de mociones por parte del Presidente de la Asamblea, y su confirmación por parte del Plenario, era considerado sin asidero pues lesionaba la facultad de enmienda de los diputados afectados por dicha medida. ${ }^{83}$ Todas estas violaciones podrían ser vistas como arreglos muy cuestionables a lo interno de la clase política que, de sobra, justificaban la desconfianza que la ciudadanía tenía hacia el gobierno y los partidos políticos cuando fue aprobado el "combo".

Debe señalarse que la mayoría de la Sala no consideró necesario pronunciarse sobre el contenido del proyecto. Contrario a esta posición, su presidente, Rodolfo Piza, envió a la Asamblea Legislativa sus objeciones al texto aprobado en primer debate. Piza sostuvo que era inadmisible la existencia de entidades privadas del 
Estado y de estructuras orgánicas más allá de las empresas públicas. Por otra parte, señaló que la radiodifusión no era un servicio público ni privado, sino una libertad democrática: aquella fundamentada en la de expresión. De ahí que era inconstitucional que el proyecto calificara la radiodifusión como servicio, sin especificar que era público. Adicionalmente, para Piza resultaba inconstitucional el traslado de $ф 80.000$ millones, provenientes del superávit acumulado del ICE, hacia el Ministerio de Hacienda como contribución a la deuda interna del Estado. Esta objeción se fundamentaba en que no era posible imponer subejecuciones o superávit a las instituciones y empresas públicas. Asimismo era imposible la donación de recursos al Estado, ya fuera de manera voluntaria o forzosa, para cualquier propósito que deba ser financiado mediante recursos tributarios ajenos a la especialidad funcional de cada entidad.$^{84}$ En fin, las observaciones de fondo realizadas por Piza, parecían apoyar al modelo de Estado vigente en la segunda posguerra.

En cualquier caso, la sentencia realizada sobre los asuntos de procedimiento -que lejos de ser cuestiones meramente formales hacían alusión a un estilo y a una concepción de gobierno- tuvo significativos efectos sobre la labor de la Comisión Mixta conformada durante las negociaciones y acogida en el seno de la Asamblea Legislativa.

\section{Las dificultades de la Comisión Mixta}

La Comisión Mixta fue aprobada por la Asamblea Legislativa el 6 de abril de 2000 , e instalada el 24 del mismo mes ${ }^{85} \mathrm{Y}$ a pesar de que la creación de dicha Comisión resultó la salida más adecuada al conflicto, su dinámica tuvo problemas insalvables en el marco Legislativo.

En primer lugar, desde sus inicios, el Departamento de Servicios Técnicos del Congreso encontró "vicios de nulidad" y de constitucionalidad en la moción que la había creado. Entre los principales problemas se encontraba el que los diputados no podían retirar proyectos de ley de la corriente legislativa durante el período de sesiones extraordinarias. Se objetó, igualmente, que el retiro del plan por un plazo de 150 días, carecía de especificación respecto de si se trataba de días hábiles o naturales. Además, no existía indicación respecto del plazo que tendría la comisión para rendir su dictamen. Aún más, el compromiso de las fracciones parlamentarias de no dar trámite a ningún proyecto de ley relacionado con el ICE limitaba, desde la perspectiva de dicho Departamento, el derecho de iniciativa de los diputados ${ }^{86}$ Estas diferencias no pudieron ser subsanadas durante todo el período de trabajo de la comisión.

Otro de los escollos fue la discrepancia entre la fracción oficialista y el Partido Libertario, por una parte; y Liberación Nacional, Fuerza Democrática y la Representación Social, por otra, respecto a la metodología de trabajo. Estas diferencias amenazaron, por momentos, la continuidad de la Comisión Mixta. 
La metodología, finalmente elegida, no permitió un avance expedito. Y si bien se avanzó en el diagnóstico de la situación del ICE, quedó pendiente la redacción y dictamen de un proyecto de ley que definiera el futuro de la institución.

El último de los problemas, que resultó definitivo para el futuro de la Comisión, se presentó el 24 de octubre, cuando la Comisión de Consultas de Constitucionalidad del Congreso acordó recomendar al plenario archivar el "combo". Dicha comisión ratificó que los vicios de inconstitucionalidad señalados por la Sala IV respecto al trámite del proyecto, eran insalvables. De esta suerte, la comisión mixta quedó sin sustento jurídico, en la medida que se había abocado a elaborar un nuevo plan del ICE tomando como referencia el expediente del "combo eléctrico". ${ }^{87}$

A pesar de que el expediente fue archivado, el Partido Unidad Social Cristiana brindó un informe de mayoría ${ }^{88}$ mientras que el Partido Liberación Nacional y Fuerza Democrática rindieron, cada uno por su parte, uno de minoría ${ }^{89}$ Estos tres informes presentaron las respectivas sugerencias sobre el futuro del ICE. Cabe señalar que, como era de esperarse, el informe de Fuerza Democrática fue el único que incluyó las propuestas de la Representación Social.

Es importante decir que, desde la perspectiva de éste último informe de minoría, los criterios de la Unión Costarricense de Cámaras y Asociaciones de la Empresa Privada; del gobierno y los diputados del PUSC, del diputado Otto Guevara y del sector social representado en la Comisión Mixta, confluían en una serie de aspectos en relación con el ICE. Entre ellos se encontraban: a) la necesidad de su despolitización; b) la necesidad de acabar con las restricciones financieras; c) la universalización del acceso a Internet; d) el estricto control de los costos de operación del ICE; e) la modificación de la composición de la Junta Directiva del ICE; f) la importancia de garantizar que todos los recursos del ICE fueran utilizados en el desarrollo de sus programas; g) la necesidad de modificar la integración de la Junta Directiva de ARESEP; y h) que se debía establecer un mecanismo claro mediante el cual el ICE rindiera cuentas al país del cumplimiento anual de sus objetivos y metas. Sin embargo, se mantuvieron los desacuerdos relacionados con la apertura al sector privado de la prestación de servicios de Internet, la apertura del mercado eléctrico y la apertura del mercado de telecomunicaciones.

Debido a las dificultades que enfrentó la Comisión Mixta y la conformación de la Asamblea Legislativa -donde los opositores al "combo" eran minoría-, todo hacía prever que, para quienes lucharon contra la reforma, la declaración de inconstitucionalidad había sido el mejor escenario posible.

Durante la negociación realizada en el TSE, lo más probable fue que ningún sector advirtiera que el proceso legislativo tendría escollos formales insalvables. De ahí que la misma "representación social" buscara asegurarse una base social que respaldara su trabajo legislativo después de la protesta y se preparara en el caso de un nuevo escenario de conflictividad en las calles. 


\section{La organización social después del movimiento en contra del "combo": La "Representación Social" y la experiencia de la "Comisión de Enlace"}

En efecto, una vez efectuada la negociación realizada el 4 de abril, que culminó con la creación de la Comisión Mixta, la llamada Representación Social (RS) percibió un repliegue de los sectores a los cuales representaban. Ante tal situación consideró necesario evitar un distanciamiento con los grupos de referencia, así como "estar preparados para la eventualidad de nuevas movilizaciones si se intentaba revivir el COMBO o desconocer la Comisión"..$^{90}$

Con este propósito la RS se planteó tres objetivos. El primero era "crear y sostener una red de información bidireccional entre la Representación Social y los distintos sectores y organizaciones que participaron durante las luchas contra el Combo". El segundo buscaba "iniciar la discusión de una serie de principios que permitieran elaborar un proyecto de ley de fortalecimiento del ICE ampliamente consensuado y representativo de las necesidades e intereses de los distintos sectores". Finalmente, intentaba crear "una red de estructuras sociales y sectoriales de carácter permanente que culminara en una Comisión Nacional de Enlace para el seguimiento de las propuestas presentadas en la Comisión Mixta, pero que también le permitiera al pueblo costarricense enfrentar con éxito las nuevas tareas y nuevas luchas en defensa de la Patria". ${ }^{11}$

Para estos efectos la RS elaboró un plan que buscaba generar un proceso de consultas y diálogo con las bases e involucrarlas "en la elaboración de las propuestas que se presentarían al país mediante actividades públicas". ${ }^{92}$

Para el proceso de elaboración de propuestas, la RS desarrolló un diálogo con representantes de comités de lucha, cívicos y comunales en Liberia, Cañas, Nicoya, San Carlos, Pérez Zeledón, Siquirres, Limón, Cartago, Turrialba y San Ramón; así como dos talleres de carácter nacional en San José. Igualmente desarrolló foros con el movimiento estudiantil, con organizaciones de mujeres, el movimiento ambientalista, con organizaciones indígenas y campesinas, cooperativas, sindicatos del sector público y profesionales en comunicación. En este proceso se recibieron propuestas para ser canalizadas por la RS en la Comisión Mixta. ${ }^{93}$

Producto del trabajo de este trabajo fue elaborado un Documento de Principios que sirvió de parámetro para la labor de la RS y que fue presentado el 20 de octubre en la Universidad de Costa Rica. También surgió un Proyecto de ley, presentado el 17 de noviembre en la Conferencia Episcopal. Además, la RS presentó en el mes de septiembre, un Plan de Contingencia para ICE, que fue acogido por las autoridades de la institución.

Esta experiencia, mostró las posibilidades de articulación social producto de la lucha social en contra del "combo" y, según el testimonio de la RS, la convicción de construir un ligamen estrecho con los sectores que dieron sustento a las protestas. 
Con la culminación del proceso de la Comisión Mixta, la Comisión de Enlace evolucionó hacia la Comisión Nacional de Enlace y Seguimiento (CONAES). Para mayo de 2001, este espacio estaba integrado por aproximadamente 28 organizaciones, entre las que se encontraban organizaciones ecologistas, indígenas, campesinas, cooperativas, sindicales, del movimiento de mujeres, de estudiantes universitarios/as y comités comunales. La nueva agenda de esta comisión giraba en torno a la elaboración de propuestas generales para un nuevo modelo de desarrollo, una nueva visión del Estado y de la democracia. ${ }^{94}$ Desconocemos el posterior desarrollo de esta iniciativa, pero, en ese momento, constituyó un ejemplo de construcción de tejido social resultante de la lucha social en contra del "combo".

\section{CONCLUSIÓN: LAS REPERCUSIONES POLÍTICAS DE LA LUCHA Y LA NECESIDAD DE UNA DEMOCRACIA PARTICIPATIVA}

El proceso que siguió el plan de transformación del ICE en el período 19992000 se caracterizó por una discusión, en lo fundamental, acotada al marco Parlamentario, sin que mediara mayor información ni consulta a la ciudadanía.

Una de las conclusiones de mayor relevancia que se derivó de esta coyuntura, fue la urgencia de institucionalizar canales democráticos de participación ciudadana, como mecanismos de real incidencia sobre la toma de decisiones. Este es un aspecto sentido por la ciudadanía, del cual se tiene evidencia al menos durante el proceso de lucha en contra del "combo". En ese momento, el 84,1\% de las personas entrevistadas por una de las encuestas realizadas por la Universidad de Costa Rica, señaló estar de acuerdo en que la aprobación o rechazo del "combo" debía ser determinado por las y los costarricenses mediante una consulta directa. Además, el $89.3 \%$, estaba en disposición de participar en dicha consulta popular. ${ }^{95}$ Probablemente este difundido consenso incidió durante el proceso de lucha social en contra del Tratado de Libre Comercio con Estados Unidos (TLC) que se desarrollaría a partir del año 2003. Las movilizaciones realizadas entre el 2003 y el 2007 por los opositores al TLC condujeron a que el 7 de octubre de 2007, se realizara el primer referéndum de la historia reciente del país. En el 2007 el referéndum de las urnas resultó negativo a los opositores al TLC, diferente a lo que sucedió con el referéndum de las calles del $2000 .{ }^{96}$

En esta coyuntura de lucha -la del 2000-, la ausencia de canales institucionalizados que permitieran a la ciudadanía participar en la toma de decisiones podría llevar nuevamente al uso de formas de protestas como las vividas en la coyuntura del movimiento social en contra del "combo". Efectivamente, un 37\% de los costarricenses consideraba que apoyaría en el futuro situaciones de protesta como las experimentadas y un 30\% participaría además en los desfiles y paros. Esta era 
una proporción considerablemente superior a los que pensaban que no harían nada (19\%) o que dejarían que cada sector resolviera sus problemas (15\%) ${ }^{97}$ Existía, entonces, una muy difundida legitimidad de las protestas como mecanismo de participación ciudadana a falta de otros mecanismos. La difundida protesta social en contra del TLC, parece haber cosechado los frutos de la lucha anti-combo, si bien sus resultados fueron paradójicos para los sectores anti-apertura. En todo caso, en contra del TLC igualmente pudo haberse nutrido de la experiencia local de lucha contra el "combo". Más investigación cabe al respecto.

Ahora bien, en el plazo inmediatamente posterior, la lucha del "combo" tuvo dos importantes repercusiones político-electorales en el sistema partidista. El elevado abstencionismo de las elecciones del 2002 fue una. Esta posibilidad ya era prevista, en abril de 2000, por un estudio de opinión pública realizado por la Escuela y la Maestría en Ciencias Políticas de la Universidad de Costa Rica. Estas instancias indagaron en los posibles efectos del movimiento opositor al "combo" en las elecciones nacionales del año 2002. Según los resultados, el $35.7 \%$ no votaría para la elección de presidente y un 32.8\% señaló que no lo haría para la de los diputados. ${ }^{98}$ Otro estudio posterior (noviembre de 2000) minimizó el abstencionismo, al cual ubicaba en el rango del $17 \%$ del electorado. ${ }^{99}$ Los resultados de las elecciones mostraron, finalmente, un abstencionismo del $31,16 \%$, apenas algo mayor que el de 1998 (30,01\%). No obstante, en ambas elecciones el abstencionismo superó significativamente al de los procesos anteriores. En 1994, por ejemplo, éste sólo representaba al 18,89\% de los votantes. ${ }^{100}$ Es posible que, así como los resultados de la votación del 2002 estuvieran influidos por la lucha social anti-combo, la de 1998 lo estuviera por la huelga de los maestros y de los sindicatos en 1995, a raíz del "pacto Figueres-Calderón".

Un segundo efecto de la lucha en contra del "combo", fue la ruptura del bipartidismo tal y como se había consolidado en la década de 1980. En las elecciones del 2002, el país presenció una inédita segunda ronda electoral debido a la irrupción del Partido Acción Ciudadana en el escenario partidista nacional. El PAC obtuvo un $17,57 \%$ de las votaciones, nunca alcanzado por tercera fuerza política alguna en la historia reciente. De esta elección, emergió ganador el PUSC con un 25,89\% de los votos, seguido por el PLN, que obtuvo apenas un $20,84 \%$ de la votación. Estas proporciones fueron significativamente inferiores a las que estos dos partidos obtenían durante la época bipartidista. En 1994, por ejemplo, el PLN ganó por un 39,3\% del padrón, mientras que el PUSC obtuvo un $37,91 \% .{ }^{101}$

Los motivos vinculados al porqué el PUSC se mantuvo en el gobierno en el 2002 es asunto de una indagación más detallada. Aquí podría señalarse que Abel Pacheco de la E., ganador de las elecciones, surgió como una figura no vinculada con "la clase política" asociada al "combo" y al "Pacto Figueres-Calderón". Junto con tal distancia, Pacheco había consolidado parte de su reconocimiento gracias 
a su estilo populista, forjado en buena parte en los medios televisivos. De esta manera, Pacheco aprovechó el enorme vacío dejado por el desgaste de la clase política bipartidista.

En cualquier caso, es interesante resaltar la intuición de los ejecutores de la encuesta realizada por la Escuela y la Maestría en Ciencias Políticas, ya citada, quienes indagaron la afectación de la intención de voto para las elecciones del 2002 a raíz de la lucha del "combo". Según detectó el estudio, el 65\% de las personas entrevistadas en abril de 2000, anunció que el "combo" afectaría su decisión de voto para presidente y el $57.8 \%$ señaló que modificaría su decisión para las elecciones de diputado. De esta modificación de criterios emergió Pacheco que, como se dijo anteriormente, no era identificado como parte cercana al círculo político tradicional. También de aquí emergió el PAC. Pero, lo más significativo es que parecía encontrarse el cambio del bipartidismo conocido hasta entonces.

\section{CITAS Y NOTAS}

* Una primera versión de este trabajo fue presentada para la elaboración del Capítulo Fortalecimiento de la Democracia del Séptimo Informe sobre Estado de la Nación en Desarrollo Humano Sostenible (2000). El autor quisiera agradecer profundamente a Manuel Rojas Bolaños, coordinador del Capítulo del Séptimo informe, por las importantes y generosas observaciones realizadas a dicha versión, las cuales enriquecieron el trabajo. No pocos agregados, y otras tantas modificaciones, se han realizado al trabajo original, de ahí que la responsabilidad sobre el nuevo documento sean enteramente del autor. También quisiera agradecer al Programa del Estado de la Nación por su completa anuencia a que esta nueva versión fuera publicada. Nuevamente, la responsabilidad sobre los citerios aquí emitidos son del autor.

1 La memoria tiene una gran importancia política, pues utiliza el pasado con los fines políticos del presente. Una reflexión al respecto puede encontrarse en: Menjívar Ochoa, Mauricio. "Los estudios sobre la memoria y los usos del pasado: perspectivas teóricas y metodológicas". En: Menjívar O., Mauricio; Argueta, Ricardo y Solano, Edgar. (editor). Historia y Memoria: Perspectivas Teóricas y Metodológicas. Cuaderno de Ciencias Sociales No.135, San José, Costa Rica. [FLACSO], febrero de 2005, pp. 9-28. Para ejemplos sobre la manera en que el pasado se utiliza con fines del presente en contextos específicos véase: Menjívar Ochoa, Mauricio. "Contienda política y uso del pasado en la Costa Rica de los años 40. La retórica de Rodrigo Facio y de José Figueres Ferrer, 1939-1951”. En Historia y Memoria..., pp. 49-101; Argueta, Ricardo. "La masacre del 30 de julio de 1975 en la memoria de los estudiantes de la Universidad de El Salvador". En: Idem, pp.29-48.; así como el trabajo de Solano, Edgar. "Memorias del abrazo eterno. La celebración de la Anexión del Partido de Nicoya a Costa Rica, 1924-1990”. En: Historia y Memoria..., pp.103-124.

Para un completo análisis del movimiento contra las tarifas eléctricas de 1983 véase el Capítulo 5 de: Alvarenga Ventuolo, Patricia. De vecinos a ciudadanos. Movimientos comunales y luchas cívicas en la historia contemporánea de Costa Rica. San José, Costa Rica, [EUNA/ EUCR], 2005, pp217-261. Varias referencias a las luchas de los obreros de las bananeras en 
la década de 1980 pueden encontrarse en: Rojas Bolaños, Manuel. Los años ochenta y el futuro incierto. San José, Costa Rica, [EUNED], 1992, pp.30 y subs.; Aguilar Hernández, Marielos. Costa Rica en el siglo XX: luchas sociales y conquistas laborales. Serie Cuadernos de Historia de la Cultura, No. 10, San José,costa Rica [EUCR], 2004, p.47; Rovira Mas, Jorge. Costa Rica en los años 80. $2^{\text {a }}$ ed. San José, Costa Rica: Editorial Porvenir, 1988, pp.48-50 y en Camacho, Daniel y Menjívar, Rafael. "El movimiento popular en Centroamérica: 1970-1983. Síntesis y perspectivas". En: Camacho, Daniel y Menjívar, Rafael (coordinadores). Los movimientos populares en América Latina. México, [Siglo XXI], 1989, p.104. Un análisis sobre el movimiento magisterial y sindical de 1995 puede encontrarse en Menjívar Ochoa, Mauricio. "Acciones colectivas en Costa Rica, al final del Siglo XX: entre la continuidad y el orden”. En: Revista de Ciencias Sociales: 106, 2004 (IV)-107, 2005: 55-67. y en Menjívar Ochoa, Mauricio. La otra sociedad civil: Acción política magisterial entre la hegemonía y la alteridad. Tesis para optar al Grado de Magíster Scientiae en Ciencias Políticas. San José, C.R: Universidad de Costa Rica, 1999.

3 Sobre las luchas sociales en la década de 1980 y los inicios de la de 1990 se puede ver, por ejemplo, Camacho, Daniel y Menjívar, Rafael (coordinadores). Los movimientos populares....; Rojas, Los años ochenta...; Botey Sobrado, Ana María. "El movimiento popular costarricense en el contexto de la crisis actual". En: Murillo V., Jaime (compilador). Historia de Costa Rica en el Siglo XX. 2a ed. San José, C.R.: Editorial Porvenir, 1990; Camacho, Daniel y Menjívar, Rafael (coordinadores). Movimientos populares en Centroamérica. San José, Costa Rica, [EDUCA], 1985; Edelman, Marc. Campesinos contra la Globalización. Movimientos sociales rurales en Costa Rica. San José, San José,Costa Rica, [EUCR],2005; Mora Alfaro, Jorge. Movimientos campesinos en Costa Rica. Cuaderno de Ciencias Sociales No.53. San José, Costa Rica. [FLACSO],1992; Valverde, José Manuel y Trejos P., María Eugenia. "Diez años de Luchas Urbanas en Costa Rica (1982-1992)". En: Revista de Ciencias Sociales, No. 61, septiembre 1993 Arguello, Manuel. Historia de los movimientos comunales en Costa Rica. San José, C.R.: Centro de Capacitación para el Desarrollo, 1983; Trejos, María Eugenia y Valverde, José Manuel. Las organizaciones del magisterio frente al ajuste. Cuaderno de Ciencias Sociales No.80. San José, Costa Rica,[FLACSO], 1995 Cartín, Sandra y Román, Isabel. Echando Raíces. La lucha por la tierra en Costa Rica. Documento de análisis No. 17. San José, C.R. CEPAS, 1991 D’Alolio Sánchez, Ileana. “<<Malos buses y peores tarifas $>>$. La Asociación de Desarrollo de Hatillo contra Metrocoop y el Estado, 1989. Anatomía de un movimiento social en el Área Metropolitana de San José a fines del siglo XX.”. En: Intercambio. Revista sobre Centroamérica y el Caribe. Año 4, No.5, 2007; Menjívar Ochoa, Mauricio. "Crisis del movimiento estudiantil universitario (1991-1994)". En: Revista Reflexiones, 32, marzo 1995: 9-21. Sindy Mora Una serie de balances sobre la década de los movimientos sociales durante las décadas de 1990 y de 2000, ver: Mora, Sindy. "Las disputas por los sentidos de lo político en Costa Rica: Hacia un balance de las luchas populares de la presente década. En: Modonesi, Massimo y Rebón, Julián (comps.). Una década en movimiento. Luchas populares en América Latina en el amanecer del siglo XXI. Buenos Aires: CLACSO-Proeteo Libros, 2011. Mora, Sindy. "Diez años de acciones colectivas en Costa Rica”. Revista Centroamericana de Ciencias Sociales.Vol. V (8), 2008, Mora, Sindy. "Elecciones, sociedad civil, acciones colectivas y movimiento social". En: Rojas, Manuel y Castro, Mariela (comps.). Elecciones 2006 y referendum. Perspectivas diversas. San José, C.R.: FLACSO, 2009. Un balance general del período comprendido entre 1979 y 2007 puede encontrarse en Menjívar Ochoa, Mauricio. "Luchas sociales en Costa Rica: de la crisis a la resistencia global". En: Santana, Adalberto (coord.). Costa Rica en los inicios del 
siglo XXI. México, UNAM, [Centro de Investigaciones sobre América Latina y el Caribe], 2008.

4 Una interesante perspectiva al respecto se encuentra en Alvarenga, De vecinos a ciudadanos.., Véase particularmente el Capítulo 6 (pp.265-298), dedicado a "La protesta cívica del 2000...".

5 El sobre-nombre de "Combo energético" o "Combo del ICE, tiene sus antecedentes en la fusión de tres proyectos que fueron presentados en el mes de septiembre de 1998 por el gobierno de Miguel Ángel Rodríguez y que poco diferían de los presentados en agosto de 1996 por el Gobierno de José María Figueres. Se trataba de la Ley de fortalecimiento del ICE, de la Ley general de electricidad y la de telecomunicaciones, que buscaban, entre otros elementos, abrir a la competencia el mercado de telecomunicaciones mediante la participación privada. Puede verse, al respecto: Herrera Herrera, Berlioth. "Discusión sobre "combo energético'. Avanza fundición de planes". La Nación Digital, domingo 24 de octubre, 1999. http://wvw.nacion.com/ln_ee/1999/octubre/24/pais2.html Último acceso: 2 de febrero de 2011 y Herrera, Berlioth. "Legisladores valoran agenda Idea para unir planes del ICE". La Nación Digital, viernes 7 de mayo, 1999. http://wvw.nacion.com/ln_ee/1999/mayo/07/pais6. html. Último acceso: 2 de febrero de 2011.

6 La presente investigación es un análisis de coyuntura, mediante el cual se busca decodificar la realidad política de manera ordenada. El análisis de coyuntura busca dar cuenta del comportamiento de las fuerzas sociales en el escenario político. Con este fin, un primer momento de esta investigación consistió en la identificación y sistematización de fuentes periodísticas, así como de documentos de diferente índole, tales como los producidos por algunas de las organizaciones, encuestas de opinión y documentos oficiales referidos a la coyuntura de lucha social estudiada. En un segundo momento, se analizó dicha información buscando entender la lógica de los diferentes agentes durante éste período, sus motivaciones, objetivos e intereses, sus articulaciones, alianzas y diferencias, sus estrategias de lucha y los escenarios en los que dichos factores se desplegaron. Un buen instructivo al respecto de los procedimientos para realizar un análisis de coyuntura puede encontrarse en: Instituto Centroamericano de Estudios Polítics (INCEP). Cómo hacer un análisis de coyuntura. Elementos para el análisis político. Cuadernos de Formación para la práctica democrática No. 5. Guatemala, [INCEP], septiembre de 2005.

$7 \quad$ Federación de Estudiantes de la Universidad de Costa Rica. Informe de Trabajo de la Comisión de Asuntos Nacionales de la Federación de Estudiantes de la Universidad de Costa Rica, 1998-2000. Costa Rica, [FEUCR], 2000.

Otro $13 \%$ no conocía el proyecto lo suficiente como para emitir opinión y un $20.2 \%$ estaba de acuerdo. Ver IIS/IIP. La Opinión Pública Costarricense en Torno al “Combo del ICE”. San Pedro de Montes de Oca: Universidad de Costa Rica, 2000, pp. 9-11. Para una versión publicada véase: Campos R., Domingo y Raventós V., Ciska. "Combo del ICE en el momento culminante de las protestas. Sondeo telefónico 24-25 de marzo del 2000”. En: Revista de Ciencias Sociales: 106, 2004 (IV)-107, 2005 (I): 35-43.

IIS/IIP, La Opinión Pública Costarricense ..., pp. 9-11.

10 Esta encuesta telefónica fue realizada los días 17, 18, 24 y 25 de mayo del 2000. Véase: Instituto de Investigaciones Sociales e Instituto de Investigaciones Psicológicas. Cruces de 
variables de la Segunda Encuesta de Opinión Pública en Torno al “Combo del ICE”. San Pedro de Montes de Oca, [IS/IIP-Universidad de Costa Rica], 2000. Una versión publicada se encuentra ben: Raventós V., Ciska y Campos R., Domingo. "Combo del ICE después de las protestas. Segundo sondeo telefónico entre el 15 y el 25 de mayo del 2000". En: Revista de Ciencias Sociales: 106, 2004 (IV)-107, 2005 (I): 45-53.

11 Patricia Alvarenga ha identificado sectores con intereses específicos, que confluyeron en esta lucha. Entre ellos, tal es el caso "de los muelleros a quienes el gobierno no había cancelado sus compensaciones" y de "los taxistas que se oponían al impuesto selectivo de combustible”. Ver Alvarenga, De vecinos a ciudadanos..., pp. 285-286. No obstante, estas demandas no tuvieron la visibilidad ni el impacto de aquellas enarboladas por los campesinos. En todo caso, como se analizará adelante, la confluencia de todos estos intereses potenciaron la lucha en contra del "combo".

12 UNIMER. Segunda encuesta nacional de opinión del año 2000. UNIMER /La Nación. La Nación Digital, Costa Rica, 2000, http://wvw.nacion.com/ln_ee/encuestas/unimer/6-2000/ encuesta.htm, último acceso 19 de Julio de 2011. La muestra es de 1203 personas (49.4\% hombres y $50.6 \%$ mujeres), cuya selección fue realizada con un diseño muestral probabilístico, estratificado por zona geográfica y polietápico. Se utilizo la cartografía del Censo de Población y Vivienda de 1984, que se actualizó en 1986, de la Dirección General de Estadística y Censos. Para la estratificación de la muestra se dividió el territorio nacional en: Área Metropolitana, Resto del Valle Central Urbano, Resto del Valle Central Rural, Resto del País Urbano, Resto del País Rural. La muestra tiene un nivel de confianza del 95\% y un error máximo de $2.8 \%$.

13 UNIMER Segunda encuesta nacional...

14 IIS/IIP. Cruces de variables....

15 Otro $23.5 \%$ asoció las causas de las protestas a "otros" factores. UNIMER, Segunda encuesta nacional...

16 UNIMER, Segunda encuesta nacional.

17 Menjívar Ochoa, La otra sociedad civil..., pp.46-47.

18 Entrevista realizada a miembros de la Representación Social el 24 de marzo del 2000.

19 Ver, Artavia, Fernando, "Iglesia y conflicto social: los obispos frente al <<Combo>>". En: Revista de Ciencias Sociales: 106, 2004 (IV)-107, 2005 (I): 69-82, p.71.

20 Estas instancias agrupaban a alrededor de 30 organizaciones.

21 Herrera, Mauricio y Vargas, Alejandro. “'Combo eléctrico' Tema ambiental enciende pugna”. La Nación Digital, Costa Rica, miércoles 26 de enero, 2000. http://wvw.nacion. com/ln_ee/2000/enero/26/pais1.html. Último acceso: 2 de febrero de 2011.

22 FEUCR, Informe de Trabajo...

23 Morales, Dennis y Otros. "Carta al Rector Macaya”. En: Semanario Universidad del 29 de marzo al 4 de abril de 2000, No. 1382. [p. 21].

24 FEUCR, Informe de Trabajo... 
25 Consejo Universitario UCR y Consejo Institucional ITCR. "Pronunciamiento sobre el proyecto de Ley para el Mejoramiento de Servicios Públicos de Electricidad y Telecomunicaciones y de la Participación del Estado". En: Semanario Universidad del 22 al 28 de marzo, No.1381, 2000, [p. 12].

26 Un hecho relevante en este contexto es la participación del Rector de la Universidad de Costa Rica, en la marcha estudiantil del viernes 17 de marzo del 2000. El Rector Gabriel Macaya señaló que esta decisión se sustentaba en el análisis que la Universidad había realizado sobre el proyecto, del que había surgido una opinión mayoritariamente contraria. El Rector Macaya sostuvo que "alimentado por estos debates, y después de un análisis cuidadoso del proyecto", tomó la decisión de acompañar a los estudiantes universitarios en su marcha". El proyecto que había defendido Macaya en el proceso concertación nacional, a juicio del Rector había sido tergiversada en su contenido, dado que algunos de los capítulos y artículos introducidos en el texto hacían el conjunto del proyecto indefendible, como es el caso del "manejo de las concesiones del espectro radioeléctrico, el acceso a parques nacionales para el desarrollo de proyectos de generación eléctrica (geotérmicos), y muchos sutiles cambios que hacen pensar que los intereses ahora en juego son otros muy distintos a los de la modernización del ICE". Véase Macaya, Gabriel. "Por qué acompañé a los estudiantes". En: Semanario Universidad del 22 al 28 de marzo, No. 1381, 2000. [p. 16].

27 Menjívar Ochoa, "Crisis del movimiento estudiantil..."

28 Huertas J., Lisbeth. "El campus se abrió al debate”. En: Semanario Universidad, Edición Extraordinaria, 2000. [p.2].

29 Botey, "El movimiento popular costarricense...", p.191-192.

30 Rojas Manuel (coordinador), Guzmán, J.; Zeledón, F.; Menjívar O., M. y Arias, R. Séptimo Informe sobre el Estado de la Nación en Desarrollo Humano Sostenible (2000). Capítulo Fortalecimiento de la Democracia (formulación preliminar). San José, Costa Rica, [Proyecto Estado de la Nación en Desarrollo Humano Sostenible], junio 7, 2001, p.15.

31 Este número puede adolecer de subestimaciones. Ha sido construido a partir del seguimiento del movimiento que realizó el periódico La Nación (La Nación Digital). El dato suministrado por el Ministerio de Seguridad tuvo el inconveniente de la excesiva agregación de información, lo cual subestimaba aún más el número de actos de protesta.

32 Se contabilizó un paro por cada institución: por ejemplo, el 30 de marzo UNDECA anunció paros totales y parciales en 82 centros del sistema de salud, los cuales son contabilizados como 82 actos de protesta. En este caso, de haberse contabilizado sólo un acto de protesta, se habría minimizado las dimensiones reales de la movilización.

33 Flores, María. "La Globalización sitia al Gobierno". En: Semanario Universidad, del 22 al 28 de marzo, No.1381, 2000, [p. 3].

34 El 27 de marzo, Joseph Salazar fue el primero en levantar la huelga de hambre, por razones de salud, seguido por Albin Solano (28 de marzo), Roberto Zamora (30 de marzo), y, por último, por Dimitri Fernández (31 de marzo). En total, este último estudiante cumplió con 12 días de huelga. Ver Ruiz, Fabiola. "Estudiantes en Huelga de Hambre. Una Lucha por la Dignidad”. En: Semanario Universidad del 5 al 11 de abril de 2000, No 1383, [.p. 5]. 
Menjívar Ochoa, La otra sociedad civil..., op. cit., p.51.

36 Recuento del 17 de marzo al 5 de abril, con base en La Nación Digital.

37 IIS/IIP. Cruces de variables..., p.17.

38 IIS/IIP. Cruces de variables.... Recuérdese que el 24 y 25 de marzo tuvo lugar el estudio.

39 UNIMER, Segunda encuesta nacional.

40 Venegas, Ismael. "Proponen más horas de trabajo legislativo". La Nación Digital, martes 22 febrero, 2000. http://wvw.nacion.com/ln_ee/2000/febrero/22/pais4.html. Último acceso: 2 de febrero de 2011.

41 Menjívar Ochoa, La otra sociedad civil..., p.50.

42 Marín Cañas, Kattia. "La tiranía de los medios de comunicación: un análisis necesario". En: Revista de Ciencias Sociales: 106, 2004 (IV)-107, 2005: 83-91, p.85.

43 Herrera, Mauricio. "Gobierno y sindicatos Intentan abrir diálogo por Combo". La Nación Digital, Costa Rica, miércoles 29 de marzo, 2000. http://wvw.nacion.com/ln_ee/2000/ marzo/29/pais1.html. Último acceso: 2 de febrero de 2011.

44 Delgado, Edgar. "Más reacciones por plan del ICE”. La Nación Digital, viernes 10 de marzo, 2000. En: http://wvw.nacion.com/ln_ee/2000/marzo/10/pais13.html. Último acceso: 2 de febrero de 2011.

45 Ruiz, Fabiola. “Capítulo de Telecomunicaciones. ¿Más orden o más privilegios?” En: Semanario Universidad del 22 al 28 de marzo 2000, No.1381. p. 4. El capítulo de telecomunicaciones, según Fabiola Ruiz, fue elaborado e introducido en la ley por el abogado Federico Malavassi para CANARA.

46 Herrera, Mauricio. "Gobierno y sindicatos intentan...", op. cit.

47 Villalobos, Carlos. "Diputados sesionan hoy Corrales pide no votar 'combo'. La Nación Digital, Sábado 18 de marzo, 2000. http://wvw.nacion.com/ln_ee/2000/marzo/18/pais3. html. Último acceso: 2 de febrero de 2011.

48 Villalobos, Carlos. "Nuevas gestiones por 'combo" ". La Nación Digital, sábado 25 de marzo, 2000. http://wvw.nacion.com/ln_ee/2000/marzo/25/pais1.html. Último acceso: 2 de febrero de 2011.

49 Aguilar, Paulo; Salas, Bertold y Estrada, María. "Hablar no es Retroceder". En: Semanario Universidad del 29 de marzo al 4 de abril, no.1382, 2000, [.p. 5].

50 Alvarenga, op. cit., p.277.

51 IIS/IIP, Cruce de variables..., op. cit.

52 Venegas, Ismael. "Plan sobre el ICE Gobierno intensifica contactos". Último acceso: 2 de febrero de 2011. La Nación Digital, Costa Rica, martes 18 de enero, 2000. http://wvw.nacion. com/ln_ee/2000/enero/18/pais10.html. Último acceso: 2 de febrero de 2011. 
54 Herrera, Mauricio. "PLN amenaza con no ratificar plan. Más presión por ICE”. La Nación Digital, Costa Rica, jueves 30 de marzo, 2000. http://wvw.nacion.com/ln_ee/2000/marzo/30/ pais1.html. Último acceso: 2 de febrero de 2011.

55 Alvarenga, op.cit., p.275

56 Herrera, Berlioth. "Adelante con plan ICE Rodríguez defiende reformas". La Nación Digital, domingo 26 de marzo, 2000. http://wvw.nacion.com/ln_ee/2000/marzo/26/pais1. html. Último acceso: 2 de febrero de 2011.

57 Ramírez, Alexánder. "Rafael Sequeira: 'Sectores con mentalidad obsoleta están tratando de destruir al ICE”". En: La Nación Digital, lunes 24 de enero, 2000.

58 Segnini, Gianinna. "Ocho entidades concentradas en Seguridad Pública. Comando atiende crisis". La Nación Digital, miércoles 22 de marzo, 2000. http://wvw.nacion.com/ln_ee/2000/ marzo/22/pais3 html. Último acceso: 2 de febrero de 2011.

59 Herrera, Berlioth. "Políticos con guantes de seda". La Nación Digital, martes 28 de marzo, 2000. http://wvw.nacion.com/ln_ee/2000/marzo/28/pais2.html. Último acceso: 2 de febrero de 2011.

60 Segnini, Giannina. "Ocho entidades concentradas...", op. cit.

61 Herrera, Berlioth. “Adelante con plan ICE ...”, op. cit.

62 Moya, Rónald. "Propuesta de ANDE y APSE sobre "combo" Rodríguez acepta mediación”. La Nación Digital, domingo 26 de marzo, 2000. http://wvw.nacion.com/ln_ee/2000/ marzo/26/pais2.html. Último acceso: 2 de febrero de 2011.

63 Herrera, Mauricio. "Gobierno y sindicatos intentan...", op. cit.

64 Moya, Rónald, "Propuesta de ANDE y APSE..."

65 Entrevista realizada a miembros de la Representación Social el 24 de marzo del 2000.

66 Herrera, Mauricio. "Gobierno y sindicatos intentan..."

67 Herrera, Mauricio. "PLN amenaza con no ratificar plan...", y Venegas, Ismael. "Congreso volvería lunes, dice Gobierno". La Nación Digital, Costa Rica, miércoles 29 de marzo, 2000. http://wvw.nacion.com/ln_ee/2000/marzo/29/pais3.html. Último acceso: 2 de febrero de 2011. Debe recordarse que la Asamblea Legislativa no trabajaba desde el martes 21 de marzo, cuando el Poder Ejecutivo retiró los proyectos de la agenda de sesiones extraordinarias.

68 Una síntesis de las visiones recientes sobre la conflictividad de la década de 1940 puede encontrarse en: Díaz Arias, David. Reforma sin alianza, discursos transformados, interés electoral, triunfos dudosos. La nueva interpretación histórica de la década de 1940. Serie Cuadernos de Historia de las Instituciones de Costa Rica No.7. San José, Costa Rica, [EUCR], 2003. Para más detalles sobre la "Huelga de brazos caídos", ver a partir de la página 30.

Herrera, Mauricio. "Gobierno y sindicatos intentan...”. 
70 Venegas, Ismael. "Modernización del ICE Sindicatos piden aplazar diálogo". La Nación Digital, domingo 2 de abril, 2000. http://wvw.nacion.com/ln_ee/2000/abril/02/pais2.html. Último acceso: 2 de febrero de 2011.

71 Villalobos, Carlos, "Inactividad en Limón y Caldera. Protesta paralizó muelles". La Nación Digital, martes 4 de abril, 2000. http://wvw.nacion.com/ln_ee/2000/abril/04/pais1.html. Último acceso: 2 de febrero de 2011.

72 Segnini, Gianinna. "No las abastecen desde sábado. Gasolineras sin combustibles". La Nación Digital, miércoles 5 de abril, 2000. http://wvw.nacion.com/ln_ee/2000/abril/05/ pais3.html. Último acceso: 2 de febrero de 2011.

73 Entrevista realizada a miembros de la Representación Social el 24 de marzo del 2000.

74 Villalobos, Carlos. "Postergan trámite de proyecto por 150 días "combo" a comisión mixta". La Nación Digital, miércoles 5 de abril, 2000. http://wvw.nacion.com/ln_ee/2000/abril/05/ pais1.html. Último acceso: 2 de febrero de 2011.

UNIMER, Segunda encuesta nacional...

UNIMER, Segunda encuesta nacional...

77 Villalobos, Carlos. "Estira y encoge marcó el diálogo". La Nación Digital, miércoles 5 de abril, 2000. http://wvw.nacion.com/ln_ee/2000/abril/05/pais2.html. Último acceso: 2 de febrero de 2011 .

78 Mientras que la mitad de la opinión ciudadana señaló que fue el pueblo fue el máximo ganador, el 13\% consideraba que era el país y el 12\% que los trabajadores. Véase UNIMER, Segunda encuesta nacional...

79 Escuela y Maestría de Ciencias Políticas. El "Combo del ICE” y la intención de voto del 2002. Universidad de Costa Rica, San Pedro de Montes de Oca, 7 de abril de 2000. El estudio contempla una muestra de 451 entrevistas en el ámbito nacional, 237 (57.1\%) del área metropolitana y 178 (42.9\%) del resto del país. De las personas entrevistadas (todas mayores de 18 años), 214 (51.6\%) eran del sexo masculino y 201 (48.4\%) del sexo femenino. Su margen de error es de $4.81 \%$.

80 UNIMER, Segunda encuesta nacional...

81 Véase, por ejemplo: Venegas Campos, Ismael. "Diputados trabajarían hasta las 10 p. m. Plan ICE extendería sesiones". La Nación Digital, jueves 6 de enero, 2000. http://wvw. nacion.com/ln_ee/2000/enero/06/pais6.html. Último acceso: 2 de febrero de 2011; Venegas Campos, Ismael. "Plan sobre el ICE. Gobierno insistirá en 'vía rápida”". La Nación Digital, miércoles 22 de diciembre, 1999. http://wvw.nacion.com/ln_ee/1999/diciembre/22/pais3. html. Último acceso: 2 de febrero de 2011; Venegas Campos, Ismael. "Plan ICE cambia de horario. Se discutirá de 12:45 p. m. a 6 p.m.”. La Nación Digital, martes 7 de marzo, 2000. http://wvw.nacion.com/ln_ee/2000/marzo/07/pais10.html. Último acceso: 2 de febrero de 2011 y Venegas Campos, Ismael. "Proyecto sobre el ICE. PUSC apura a Liberación". La Nación Digital, sábado 26 de febrero, 2000. http://wvw.nacion.com/ln_ee/2000/febrero/26/ pais3.html. Último acceso: 2 de febrero de 2011. 
82 Sala Constitucional de la Corte Suprema de Justicia. Sentencia 3220-2000 del dieciocho de abril del dos mil.

83 Sala Constitucional de la Corte Suprema de Justicia. Sentencia 3220-2000...

84 Méndez Garita, William. "Cuestiona Icetel e Icelec. Piza objeta partir el ICE”. La Nación Digital, miércoles 3 de mayo, 2000. http://wvw.nacion.com/ln_ee/2000/mayo/03/pais10. html. Último acceso: 2 de febrero de 2011.

85 Venegas, Ismael. "Legislativa aprueba la integración de una comisión especial mixta”. En: La Nación Digital, viernes 7 de abril, 2000.

86 Venegas, Ismael. "Proyecto de reforma del ICE. Alegan nulidad de comisión". La Nación Digital, Costa Rica, miércoles 10 de mayo, 2000. http://wvw.nacion.com/ln_ee/2000/ mayo/10/pais4.html. Último acceso: 2 de febrero de 2011.

87 Venegas, Ismael. "Informe final de comisión mixta. Tras consenso por ICE". La Nación Digital, Costa Rica. Martes 24 de octubre, 2000. http://wvw.nacion.com/ln_ee/2000/ octubre/24/pais4.html. Último acceso: 2 de febrero de 2011.

88 Comisión Especial Mixta. Informe de Mayoría del Partido Unidad Social Cristiana. Asamblea Legislativa, Expediente 13919.

89 Comisión Especial Mixta. Informe de Minoría del Partido Liberación Nacional. Asamblea Legislativa, Expediente 13919 y Comisión Especial Mixta. Informe de Minoría del Partido Fuerza Democrática. Asamblea Legislativa, Expediente 13919.

90 Mora, Jorge. Las Nuevas Tendencias de la Organización y Movilización Populares en el Contexto de las Luchas contra el combo del ICE. (miemeo), San José, Costa Rica, 2001, p. 19.

91 Representación Social. Comisión Especial Mixta del ICE, 2000. Informe Final (resumen). San José: La Representación, p.3.

92 Mora Las Nuevas Tendencias..., p. 20.

93 Representación Social, Informe Final..., pp. 3-4.

94 Mora, Las Nuevas Tendencias..., p. 21.

95 Otro $6.3 \%$ señala que no participaría y un $4.3 \%$ no sabía. Ver: IIS/IIP. La Opinión Pública Costarricense..., op.cit.

96 El referéndum fue aprobado con una participación del 59,2\% del electorado. Del total de estos votantes, un $51.2 \%$ votó por el "sî́" y un $48 \%$ lo hizo por el "no". Tribunal Supremo de Elecciones, \#2944-E-2007. Declaratoria Oficial del Referéndum. Una versión electrónica se encuentra en: http://www.tlc-costarica.com/2007/10/declaratoria-oficial-referendum.html. Un sucinto análisis sobre la lucha en contra del TLC se puede encontrar en Menjívar Ochoa, Mauricio. "Luchas sociales en Costa Rica: de la crisis a la resistencia global (1979-2007)", inédito.

UNIMER, Segunda encuesta nacional.

Escuela y Maestría de Ciencias Políticas, El “Combo del ICE”... 
99 UNIMER, 2000. Tercera encuesta nacional de opinión del año 2000. UNIMER /La Nación. La Nación Digital, Costa Rica. http://wvw.nacion.com/ln_ee/encuestas/unimer/10-2000/ encuesta.html, último acceso: 19 de Julio de 2011.

100 Rodríguez, Florisabel, Espinoza, Rowland y Madrigal, Johnny. "El final del bipartidismo en Costa Rica: un retrato electoral 1994-2002”. En: Revista de Ciencias Sociales 109-110 (IIIIV), 2005: 15-29, pp.17-21.

101 Rodríguez, Espinoza y Madrigal, "El final del bipartidismo...”.

\section{BIBLIOGRAFÍA}

Aguilar Hernández, Marielos. Costa Rica en el siglo XX: luchas sociales y conquistas laborales. Serie Cuadernos de Historia de la Cultura, No. 10, San José, C.R.: EUCR, 2004.

Alvarenga Ventuolo, Patricia. De vecinos a ciudadanos. Movimientos comunales y luchas cívicas en la historia contemporánea de Costa Rica. San José, C.R.: EUNA/EUCR, 2005.

Arguello, Manuel. Historia de los movimientos comunales en Costa Rica. San José, C.R.: Centro de Capacitación para el Desarrollo, 1983.

Argueta, Ricardo. "La masacre del 30 de julio de 1975 en la memoria de los estudiantes de la Universidad de El Salvador". En: Menjívar O., Mauricio; Argueta, Ricardo y Solano, Edgar. (editor). Historia y Memoria: Perspectivas Teóricas y Metodológicas. Cuaderno de Ciencias Sociales No.135, San José, C.R. FLACSO, febrero de 2005.

Artavia, Fernando, "Iglesia y conflicto social: los obispos frente al <<Combo >>". En: Revista de Ciencias Sociales: 106, 2004 (IV)-107, 2005 (I): 69-82.

Botey Sobrado, Ana María. "El movimiento popular costarricense en el contexto de la crisis actual”. En: Murillo V., Jaime (compilador). Historia de Costa Rica en el Siglo XX. $2^{\mathrm{a}}$ ed. San José, C.R.: Editorial Porvenir, 1990.

Camacho, Daniel y Menjívar, Rafael (coordinadores). Los movimientos populares en América Latina. México: Siglo XXI, 1989.

Camacho, Daniel y Menjívar, Rafael. "El movimiento popular en Centroamérica: 1970-1983. Síntesis y perspectivas”. En: Camacho, Daniel y Menjívar, Rafael (coordinadores). Los movimientos populares en América Latina. México: Siglo XXI, 1989.

Camacho, Daniel y Menjívar, Rafael (coordinadores). Movimientos populares en Centroamérica. San José, C.R.: EDUCA, 1985.

Campos R., Domingo y Raventós V., Ciska. "Combo del ICE en el momento culminante de las protestas. Sondeo telefónico 24-25 de marzo del 2000”. En: Revista de Ciencias Sociales: 106, 2004 (IV)-107, 2005 (I): 35-43.

Cartín, Sandra y Román, Isabel. Echando Raíces. La lucha por la tierra en Costa Rica. Documento de análisis No. 17. San José, C.R.. CEPAS, 1991. 
Contreras, Gerardo. La globalización económica desde los paradigmas del mercado y la solidaridad humana. Serie Cuadernos de Historia de la Cultura, No.2, San José, C.R.: EUCR, 2007.

D’Alolio Sánchez, Ileana.“<<Malos buses y peores tarifas $>>$. La Asociación de Desarrollo de Hatillo contra Metrocoop y el Estado, 1989. Anatomía de un movimiento social en el Área Metropolitana de San José a fines del siglo XX.”. En: Intercambio. Revista sobre Centroamérica y el Caribe. Año 4, No.5, 2007 (en prensa).

Díaz Arias, David. Reforma sin alianza, discursos transformados, interés electoral, triunfos dudosos. La nueva interpretación histórica de la década de 1940. Serie Cuadernos de Historia de las Instituciones de Costa Rica No.7. San José, C.R.: EUCR, 2003.

Edelman, Marc. Campesinos contra la Globalización. Movimientos sociales rurales en Costa Rica. San José, C.R.: EUCR, 2005.

Instituto Centroamericano de Estudios Políticos (INCEP). Cómo hacer un análisis de coyuntura. Elementos para el análisis político. Cuadernos de Formación para la práctica democrática No. 5. Guatemala: INCEP, septiembre de 2005.

Marín Cañas, Kattia. "La tiranía de los medios de comunicación: un análisis necesario". En: Revista de Ciencias Sociales: 106, 2004 (IV)-107, 2005: 83-91.

Menjívar Ochoa, Mauricio. "Luchas sociales en Costa Rica: de la crisis a la resistencia global”. En: Santana, Adalberto (coord.). Costa Rica en los inicios del siglo XXI. México: UNAM Centro de Investigaciones sobre América Latina y el Caribe, 2008.

Menjívar Ochoa, Mauricio. “Acciones colectivas en Costa Rica, al final del Siglo XX: entre la continuidad y el orden”. En: Revista de Ciencias Sociales: 106, 2004 (IV)-107, 2005: 55-67.

Menjívar Ochoa, Mauricio. “Contienda política y uso del pasado en la Costa Rica de los años 40. La retórica de Rodrigo Facio y de José Figueres Ferrer, 1939-1951”. En: Menjívar O., Mauricio (editor); Argueta, Ricardo y Solano, Edgar. Historia y Memoria: Perspectivas Teóricas y Metodológicas. Cuaderno de Ciencias Sociales No.135, febrero de 2005. San José, C.R.: FLACSO, febrero de 2005.

Menjívar Ochoa, Mauricio. "Los estudios sobre la memoria y los usos del pasado: perspectivas teóricas y metodológicas”. En: Menjívar O., Mauricio; Argueta, Ricardo y Solano, Edgar. (editor). Historia y Memoria: Perspectivas Teóricas y Metodológicas. Cuaderno de Ciencias Sociales No.135, San José, C.R.: FLACSO, febrero de 2005.

Menjívar Ochoa, Mauricio. La otra sociedad civil: Acción política magisterial entre la hegemonía y la alteridad. Tesis para optar al Grado de Magíster Scientiae en Ciencias Políticas. San José, C.R: Universidad de Costa Rica, 1999.

Menjívar Ochoa, Mauricio. "Crisis del movimiento estudiantil universitario (1991-1994)”. En: Revista Reflexiones, 32, marzo 1995: 9-21.

Mora, Jorge. Las Nuevas Tendencias de la Organización y Movilización Populares en el Contexto de las Luchas contra el combo del ICE. (miemeo), San José, Costa Rica, 2001.

Mora Alfaro, Jorge. Movimientos campesinos en Costa Rica. Cuaderno de Ciencias Sociales No.53. San José, C.R.: FLACSO, 1992. 
Mora, Sindy. "Las disputas por los sentidos de lo político en Costa Rica: Hacia un balance de las luchas populares de la presente década. En: Modonesi, Massimo y Rebón, Julián (comps.). Una década en movimiento. Luchas populares en América Latina en el amanecer del siglo XXI. Buenos Aires: CLACSO-Proeteo Libros, 2011.

Mora, Sindy. "Diez años de acciones colectivas en Costa Rica”. Revista Centroamericana de Ciencias Sociales.Vol. V (8), 2008.

Mora, Sindy. "Elecciones, sociedad civil, acciones colectivas y movimiento social". En: Rojas, Manuel y Castro, Mariela (comps.). Elecciones 2006 y referendum. Perspectivas diversas. San José, C.R.: FLACSO, 2009.

Raventós V., Ciska y Campos R., Domingo. "Combo del ICE después de las protestas. Segundo sondeo telefónico entre el 15 y el 25 de mayo del 2000”. En: Revista de Ciencias Sociales: 106, 2004 (IV)-107, 2005 (I): 45-53.

Reuben Soto, Sergio. "La sociedad civil, el bienestar social y las transformaciones del Estado en Costa Rica”. En: Revista Reflexiones, 83 (1) 2004: 21-30.

Rodríguez, Florisabel, Espinoza, Rowland y Madrigal, Johnny. "El final del bipartidismo en Costa Rica: un retrato electoral 1994-2002". En: Revista de Ciencias Sociales 109-110 (III-IV), 2005: 15-29.

Rojas, Manuel, Guzmán, J.; Zeledón, F.; Menjívar O., M. y Arias, R. (coordinador). Séptimo Informe sobre el Estado de la Nación en Desarrollo Humano Sostenible (2000). Capítulo Fortalecimiento de la Democracia (formulación preliminar). San José, C.R.: Proyecto Estado de la Nación en Desarrollo Humano Sostenible, junio 7, 2001.

Rojas Bolaños, Manuel. Los años ochenta y el futuro incierto. San José, C.R.: EUNED, 1992

Rovira Mas, Jorge. Costa Rica en los años 80.2ª ed. San José, Costa Rica: Editorial Porvenir, 1988.

Solano, Edgar. "Memorias del abrazo eterno. La celebración de la Anexión del Partido de Nicoya a Costa Rica, 1924-1990”. En: Menjívar O., Mauricio; Argueta, Ricardo y Solano, Edgar. (editor). Historia y Memoria: Perspectivas Teóricas y Metodológicas. Cuaderno de Ciencias Sociales No.135, San José, C.R. FLACSO, febrero de 2005, pp.103-124.

Trejos, María Eugenia y Valverde, José Manuel. Las organizaciones del magisterio frente al ajuste. Cuaderno de Ciencias Sociales No.80. San José, C.R.: FLACSO, 1995.

Universidad de Costa Rica, Escuela y Maestría de Ciencias Políticas. El "Combo del ICE" y la intención de voto del 2002. Universidad de Costa Rica, San Pedro de Montes de Oca, 7 de abril de 2000.

Valverde, José Manuel y Trejos P., María Eugenia. "Diez años de Luchas Urbanas en Costa Rica (1982-1992)”. En: Revista de Ciencias Sociales, No. 61, septiembre 1993: 7-16.

Vargas Solís, Luís Paulino. La estrategia de liberalización económica (Período 1980-2000). Cuaderno de Historia de las Instituciones de Costa Rica, No.9. $1^{\text {a }}$ reimpresión, San José, C.R.; 2007. 


\section{FUENTES PRIMARIAS}

\section{Fuentes periodísticas}

Aguilar, Paulo; Salas, Bertold y Estrada, María. "Hablar no es Retroceder". Semanario Universidad del 29 de marzo al 4 de abril, no.1382,2000, p. 5.

Consejo Universitario UCR y Consejo Institucional ITCR. "Pronunciamiento sobre el proyecto de Ley para el Mejoramiento de Servicios Públicos de Electricidad y Telecomunicaciones y de la Participación del Estado”. Semanario Universidad del 22 al 28 de marzo, No.1381, 2000, p. 12.

Delgado, Edgar. “Más reacciones por plan del ICE”. La Nación Digital, viernes 10 de marzo, 2000. http://wvw.nacion.com/ln_ee/2000/marzo/10/pais13.html. Último acceso: 2 de febrero de 2011.

Flores, María. "La Globalización sitia al Gobierno". Semanario Universidad, del 22 al 28 de marzo, No.1381, 2000, p. 3.

Foro de la Nación. “Texto del Acuerdo”. La Nación, jueves 6 de abril del 2000, p.14 A.

Herrera, Berlioth. "Protestas y bloqueos tras aprobación de proyecto tirantez por plan del ICE". La Nación Digital, Costa Rica, Miércoles, 22 de marzo, 2000. http://wvw.nacion.com/ln_ ee/2000/marzo/22/pais1.html. Último acceso: 2 de febrero de 2011.

Herrera, Berlioth. "Adelante con plan ICE Rodríguez defiende reformas". La Nación Digital, domingo 26 de marzo, 2000. http://wvw.nacion.com/ln_ee/2000/marzo/26/pais $1 . h t m l$. Último acceso: 2 de febrero de 2011.

Herrera, Berlioth. "Políticos con guantes de seda". La Nación Digital, martes 28 de marzo, 2000. http://wvw.nacion.com/ln_ee/2000/marzo/28/pais2.html. Último acceso: 2 de febrero de 2011.

Herrera, Berlioth. "Discusión sobre 'combo energético'. Avanza fundición de planes”. La Nación Digital, domingo 24 de octubre, 1999. http://wvw.nacion.com/ln_ee/1999/octubre/24/pais2. html Último acceso: 2 de febrero de 2011.

Herrera, Berlioth. "Legisladores valoran agenda Idea para unir planes del ICE”. La Nación Digital, viernes 7 de mayo, 1999. http://wvw.nacion.com/ln_ee/1999/mayo/07/pais6.html. Último acceso: 2 de febrero de 2011.

Herrera, Mauricio. "Gobierno y sindicatos Intentan abrir diálogo por Combo". La Nación Digital, Costa Rica, miércoles 29 de marzo, 2000. http://wvw.nacion.com/ln_ee/2000/marzo/29/ pais1.html. Último acceso: 2 de febrero de 2011.

Herrera, Mauricio. "PLN amenaza con no ratificar plan. Más presión por ICE”. La Nación Digital, Costa Rica, jueves 30 de marzo, 2000. http://wvw.nacion.com/ln_ee/2000/marzo/30/pais1. html. Último acceso: 2 de febrero de 2011.

Herrera, Mauricio y Vargas, Alejandro. “'Combo eléctrico' Tema ambiental enciende pugna”. La Nación Digital, Costa Rica, miércoles 26 de enero, 2000. http://wvw.nacion.com/ln_ee/2000/ enero/26/pais 1.html. Último acceso: 2 de febrero de 2011. 
Huertas J., Lisbeth. "El campus se abrió al debate”. Semanario Universidad, Edición Extraordinaria, 2000.p.2.

Macaya, Gabriel. "Por qué acompañé a los estudiantes". Semanario Universidad del 22 al 28 de marzo, No. 1381, 2000. p. 16.

Méndez Garita, William. "Cuestiona Icetel e Icelec. Piza objeta partir el ICE”. La Nación Digital, miércoles 3 de mayo, 2000. http://wvw.nacion.com/ln_ee/2000/mayo/03/pais10.html. Último acceso: 2 de febrero de 2011.

Morales, Dennis y Otros. “Carta al Rector Macaya”. En: Semanario Universidad del 29 de marzo al 4 de abril de 2000, No. 1382.p. 21.

Moya, Rónald. "Propuesta de ANDE y APSE sobre “combo" Rodríguez acepta mediación”. La Nación Digital, domingo 26 de marzo, 2000. http://wvw.nacion.com/ln_ee/2000/marzo/26/ pais2.html. Último acceso: 2 de febrero de 2011.

Ramírez, Alexánder. "Sequeira advierte a diputados: 'El ICE se podría acabar'”. La Nación Digital, lunes 24 de enero, 2000. http://wvw.nacion.com/ln_ee/2000/enero/24/pais9.html. Último acceso: 2 de febrero de 2011.

Ruiz, Fabiola. “Capítulo de Telecomunicaciones. ¿Más orden o más privilegios?”. Semanario Universidad del 22 al 28 de marzo 2000, No.1381.p. 4.

Ruiz, Fabiola. "Estudiantes en Huelga de Hambre. Una Lucha por la Dignidad”. Semanario Universidad del 5 al 11 de abril de 2000, No 1383,p. 5.

Segnini, Gianinna. "Ocho entidades concentradas en Seguridad Pública. Comando atiende crisis". La Nación Digital, miércoles 22 de marzo, 2000. http://wvw.nacion.com/ln_ee/2000/ marzo/22/pais3.html. Último acceso: 2 de febrero de 2011.

Segnini, Gianinna. "No las abastecen desde sábado. Gasolineras sin combustibles". La Nación Digital, miércoles 5 de abril, 2000. http://wvw.nacion.com/ln_ee/2000/abril/05/pais3.html. Último acceso: 2 de febrero de 2011.

Venegas, Ismael. "Proyecto de reforma del ICE Alegan nulidad de comisión”. La Nación Digital, Costa Rica, miércoles 10 de mayo, 2000. http://wvw.nacion.com/ln_ee/2000/mayo/10/pais4. html. Último acceso: 2 de febrero de 2011.

Venegas, Ismael. “Informe final de comisión mixta. Tras consenso por ICE”. La Nación Digital, Costa Rica. Martes 24 de octubre, 2000. http://wvw.nacion.com/ln_ee/2000/octubre/24/ pais4.html. Último acceso: 2 de febrero de 2011.

Venegas, Ismael. “Avalan comisión para Combo". La Nación Digital, viernes 7 de abril, 2000. http://wvw.nacion.com/ln_ee/2000/abril/07/pais1.html. Último acceso: 2 de febrero de 2011.

Venegas, Ismael. "Modernización del ICE Sindicatos piden aplazar diálogo". La Nación Digital, domingo 2 de abril, 2000. http://wvw.nacion.com/ln_ee/2000/abril/02/pais2.html. Último acceso: 2 de febrero de 2011.

Venegas, Ismael. "Congreso volvería lunes, dice Gobierno". La Nación Digital, Costa Rica, miércoles 29 de marzo, 2000. http://wvw.nacion.com/ln_ee/2000/marzo/29/pais3.html. Último acceso: 2 de febrero de 2011. 
Venegas Campos, Ismael. "Plan ICE cambia de horario. Se discutirá de 12:45 p. m. a 6 p.m.”. La Nación Digital, martes 7 de marzo, 2000. http://wvw.nacion.com/ln_ee/2000/marzo/07/ pais10.html. Último acceso: 2 de febrero de 2011.

Venegas Campos, Ismael. "Proyecto sobre el ICE PUSC apura a Liberación”. La Nación Digital, sábado 26 de febrero, 2000. http://wvw.nacion.com/ln_ee/2000/febrero/26/pais3.html. Último acceso: 2 de febrero de 2011.

Venegas, Ismael. "Proponen más horas de trabajo legislativo". La Nación Digital, martes 22 febrero, 2000.http://wvw.nacion.com/ln_ee/2000/febrero/22/pais4.html. Último acceso: 2 de febrero de 2011.

Venegas Campos, Ismael. "Reforma del ICE acaparará sesiones extraordinarias". La Nación Digital, lunes 24 de enero, 2000. http://wvw.nacion.com/ln_ee/2000/enero/24/pais2.html. Último acceso: 2 de febrero de 2011.

Venegas, Ismael. "Plan sobre el ICE Gobierno intensifica contactos". Último acceso: 2 de febrero de 2011. La Nación Digital, Costa Rica, martes 18 de enero, 2000. http://wvw.nacion.com/ ln_ee/2000/enero/18/pais10.html. Último acceso: 2 de febrero de 2011.

Venegas Campos, Ismael. "Diputados trabajarían hasta las 10 p. m. Plan ICE extendería sesiones". La Nación Digital, jueves 6 de enero, 2000. http://wvw.nacion.com/ln_ee/2000/enero/06/ pais6.html. Último acceso: 2 de febrero de 2011.

Venegas Campos, Ismael. "Plan sobre el ICE. Gobierno insistirá en “vía rápida'”. La Nación Digital, miércoles 22 de diciembre, 1999. http://wvw.nacion.com/ln_ee/1999/diciembre/22/pais3. html. Último acceso: 2 de febrero de 2011.

Villalobos, Carlos. "Diputados sesionan hoy Corrales pide no votar 'combo'. La Nación Digital, Sábado 18 de marzo, 2000. http://wvw.nacion.com/ln_ee/2000/marzo/18/pais3.html. Último acceso: 2 de febrero de 2011.

Villalobos, Carlos. "Nuevas gestiones por “combo” ". La Nación Digital, sábado 25 de marzo, 2000. http://wvw.nacion.com/ln_ee/2000/marzo/25/pais1.html. Último acceso: 2 de febrero de 2011.

Villalobos, Carlos, “Inactividad en Limón y Caldera. Protesta paralizó muelles”. La Nación Digital, martes 4 de abril, 2000. http://wvw.nacion.com/ln_ee/2000/abril/04/pais1.html. Último acceso: 2 de febrero de 2011.

Villalobos, Carlos. "Estira y encoge marcó el diálogo". La Nación Digital, miércoles 5 de abril, 2000. http://wvw.nacion.com/ln_ee/2000/abril/05/pais2.html. Último acceso: 2 de febrero de 2011.

Villalobos, Carlos. "Postergan trámite de proyecto por 150 días "combo" a comisión mixta". La Nación Digital, miércoles 5 de abril, 2000. http://wvw.nacion.com/ln_ee/2000/abril/05/ pais1.html. Último acceso: 2 de febrero de 2011. 


\section{Otras Fuentes}

Comisión Especial Mixta. Informe de Mayoría del Partido Unidad Social Cristiana. Asamblea Legislativa, Expediente 13919.

Comisión Especial Mixta. Informe de Minoría del Partido Liberación Nacional. Asamblea Legislativa, Expediente 13919.

Comisión Especial Mixta. Informe de Minoría del Partido Fuerza Democrática. Asamblea Legislativa, Expediente 13919.

Federación de Estudiantes de la Universidad de Costa Rica. Informe de Trabajo de la Comisión de Asuntos Nacionales de la Federación de Estudiantes de la Universidad de Costa Rica, 19982000. Costa Rica: FEUCR, 2000.

Instituto de Investigaciones Sociales e Instituto de Investigaciones Psicológicas. La Opinión Pública Costarricense en Torno al "Combo del ICE". Universidad de Costa Rica, San Pedro de Montes de Oca, 2000.

Instituto de Investigaciones Sociales e Instituto de Investigaciones Psicológicas. Cruces de variables de la Segunda Encuesta de Opinión Pública en Torno al “Combo del ICE”. Universidad de Costa Rica, San Pedro de Montes de Oca, 2000.

Representación Social. Comisión Especial Mixta del ICE. Informe Final (resumen). San José, C.R.: La Representación, 2000.

Sala Constitucional de la Corte Suprema De Justicia. Sentencia 3220-2000 del dieciocho de abril del dos mil.

Tribunal Supremo de Elecciones, \#2944-E-2007. Declaratoria Oficial del Referéndum. http://www. tlc-costarica.com/2007/10/declaratoria-oficial-referendum.html. Consultado: 2 de mayo de 2008.

UNIMER, Segunda encuesta nacional de opinión del año 2000. UNIMER /La Nación. La Nación Digital, Costa Rica, 2000. http://wvw.nacion.com/ln_ee/encuestas/unimer/6-2000/encuesta. htm, último acceso: 18 de Julio de 2011.

UNIMER,. Tercera encuesta nacional de opinión del año 2000. UNIMER /La Nación. La Nación Digital, Costa Rica, 2000 San Pedro de Montes de Oca 2000. http://wvw.nacion.com/ln_ee/ encuestas/unimer/10-2000/encuesta.htm, último acceso: 19 de Julio de 2011.

\section{ACERCA EL AUTOR}

Mauricio Menjívar Ochoa: Doctor en Historia. Docente e investigador de la Escuela de Estudios Generales, Universidad de Costa Rica. Correo electrónico: mauricio.menjivar@ucr.ac.cr. 


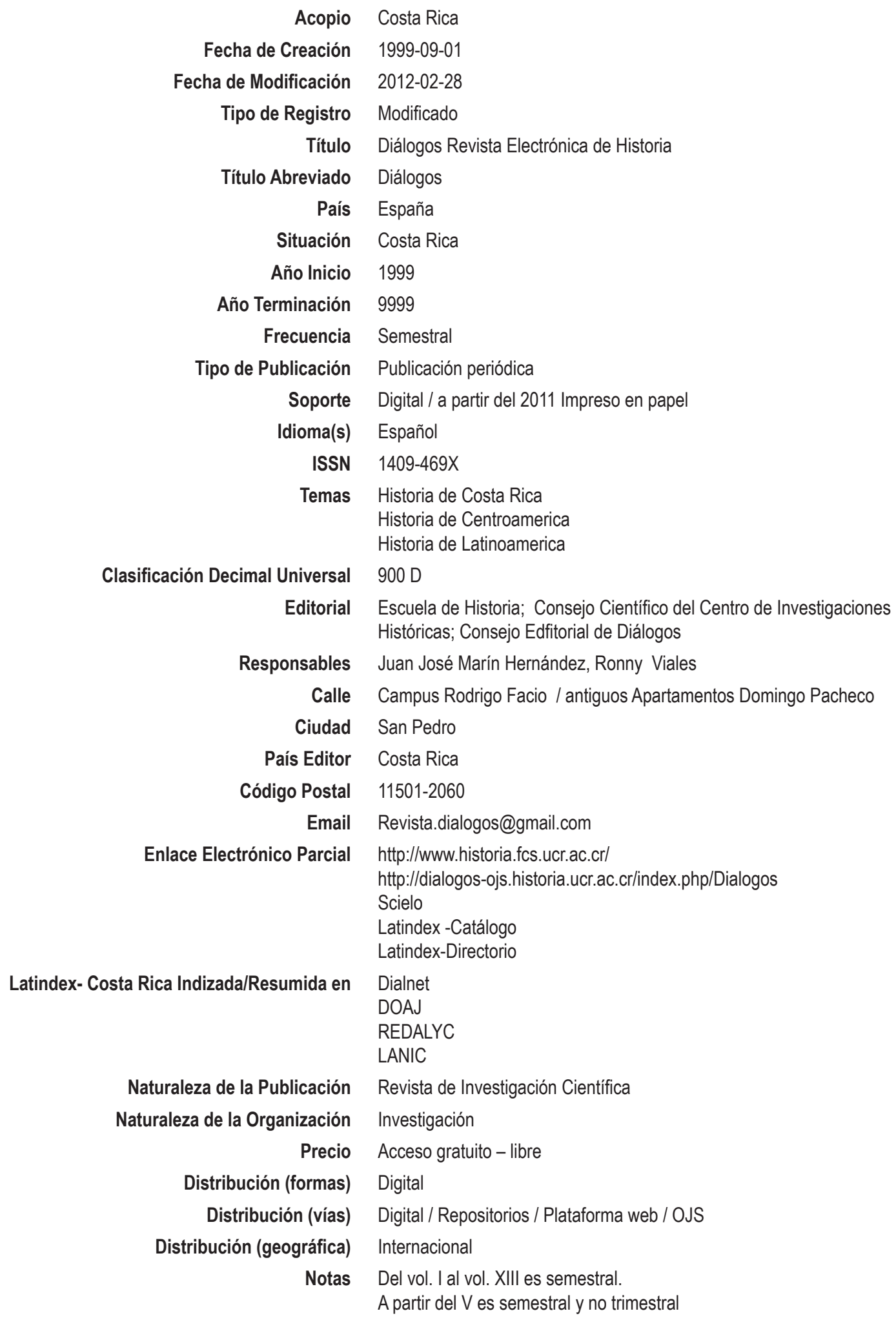

